\title{
Disruption of Critical Period Plasticity in a Mouse Model of Neurofibromatosis Type 1
}

\author{
${ }^{\circledR}$ Mariska van Lier, ${ }^{1}{ }^{\circledR}$ M. Hadi Saiepour, ${ }^{1}$ Koen Kole, ${ }^{4}$ Juliette E. Cheyne, ${ }^{3}$ Nawal Zabouri, ${ }^{3}$ Thomas Blok, ${ }^{1}$ \\ Yi Qin, ${ }^{1}$ Emma Ruimschotel, ${ }^{1}{ }^{-}$J. Alexander Heimel, ${ }^{2}$ Christian Lohmann, ${ }^{3,5}$ and ${ }^{\circledR}$ Christiaan N. Levelt ${ }^{1,6}$ \\ ${ }^{1}$ Molecular Visual Plasticity Group, Netherlands Institute for Neuroscience, Amsterdam, 1105 BA, The Netherlands, ${ }^{2}$ Cortical Structure and \\ Function Group, Netherlands Institute for Neuroscience, Amsterdam, 1105 BA, The Netherlands, ${ }^{3}$ Synapse and Network Development Group, \\ Netherlands Institute for Neuroscience, Amsterdam, 1105 BA, The Netherlands, ${ }^{4}$ Netherlands Institute for Neuroscience, Amsterdam, 1105 BA, \\ The Netherlands, ${ }^{5}$ Department of Functional Genomics, Center for Neurogenomics and Cognitive Research, VU University Amsterdam, 1081 HV, \\ The Netherlands, and ${ }^{6}$ Department of Molecular and Cellular Neurobiology, Center for Neurogenomics and Cognitive Research, VU University \\ Amsterdam, $1081 \mathrm{HV}$, The Netherlands
}

Neurofibromatosis type 1 (NF1) is a common monogenic neurodevelopmental disorder associated with physical and cognitive problems. The cognitive issues are thought to arise from increased release of the neurotransmitter GABA. Modulating the signaling pathways causing increased GABA release in a mouse model of NF1 reverts deficits in hippocampal learning. However, clinical trials based on these approaches have so far been unsuccessful. We therefore used a combination of slice electrophysiology, in vivo two-photon calcium imaging, and optical imaging of intrinsic signal in a mouse model of NF1 to investigate whether cortical development is affected in NF1, possibly causing lifelong consequences that cannot be rescued by reducing inhibition later in life. We find that, in NF1 mice of both sexes, inhibition increases strongly during the development of the visual cortex and remains high. While this increase in cortical inhibition does not affect spontaneous cortical activity patterns during early cortical development, the critical period for ocular dominance plasticity is shortened in NF1 mice due to its early closure but unaltered onset. Notably, after environmental enrichment, differences in inhibitory innervation and ocular dominance plasticity between NF1 mice and WT littermates disappear. These results provide the first evidence for critical period dysregulation in NF1 and suggest that treatments aimed at normalizing levels of inhibition will need to start at early stages of development.

Key words: critical period; environmental enrichment; inhibition; neurofibromatosis type 1; ocular dominance; spontaneous activity

Significance Statement

Neurofibromatosis type 1 is associated with cognitive problems for which no treatment is currently available. This study shows that, in a mouse model of neurofibromatosis type 1, cortical inhibition is increased during development and critical period regulation is disturbed. Rearing the mice in an environment that stimulates cognitive function overcomes these deficits. These results uncover critical period dysregulation as a novel mechanism in the pathogenesis of neurofibromatosis type 1. This suggests that targeting the affected signaling pathways in neurofibromatosis type 1 for the treatment of cognitive disabilities may have to start at a much younger age than has so far been tested in clinical trials.

Received Sep. 16, 2019; revised May 4, 2020; accepted May 7, 2020.

Author contributions: M.v.L., M.H.S., J.A.H., C.L., and C.N.L. designed research; M.v.L., M.H.S., K.K., J.E.C., N.Z., T.B., Y.Q., E.R., and J.A.H. performed research; M.v.L., M.H.S., K.K., J.E.C., N.Z., T.B., E.R., J.A.H., and C.L. analyzed data; M.v.L. wrote the first draft of the paper; K.K., J.E.C., T.B., J.A.H., C.L., and C.N.L. edited the paper; C.L. and C.N.L. contributed unpublished reagents/analytic tools; C.N.L. wrote the paper.

This work was supported by an AgentschapNL grant to the NeuroBasic PharmaPhenomics consortium to C.N.L., Young Investigator Award from the Children's Tumor Foundation to M.v.L., Nederlandse Organisatie voor Wetenschappelijk Onderzoek Grant 823.02.001 to C.N.L., Stichting Blindenhulp and Stichting Vrienden van het Nederlands Herseninstituut, Praktijkgenerator, Tijn de Lange, and Vidi Grant to J.A.H. We thank Dr. Maarten Kole for support and advice on electrophysiological recordings.

The authors declare no competing financial interests.

Correspondence should be addressed to Christiaan N. Levelt at c.levelt@nin.knaw.nl.

https://doi.org/10.1523/JNEUROSCI.2235-19.2020

Copyright $\odot 2020$ the authors

\section{Introduction}

Neurofibromatosis type 1 (NF1) is a monogenic autosomal dominant neurodevelopmental disorder caused by a heterozygous mutation in the NF1 gene, with an incidence of 1:3000. Dominant symptoms are café-au-lait spots, neurofibromas, and Lisch nodules (Cnossen et al., 1998; Ferner et al., 2007). Additionally, most NF1 patients exhibit cognitive symptoms, including learning disabilities, reduced visuospatial skills, motor delays, social deficits, and attention deficit disorder (Schrimsher et al., 2003; Hyman et al., 2005; Williams et al., 2009; Champion et al., 2014). Many suffer from autism (Krab et al., 2008a, 2009). 
A mouse model of NF1, in which one $n f 1$ allele is deleted, has been used to investigate molecular mechanisms underlying these cognitive problems. $\mathrm{N} f 1^{+/-}$mice show spatial learning and attention deficits, similar to NF1 patients (Silva et al., 1997). Studies using $n f 1^{+/-}$mice demonstrated that increased neuronal inhibition underlies cognitive and learning deficits in NF1 (Costa et al., 2002; Cui et al., 2008; Shilyansky et al., 2010; Gonçalves et al., 2017), an idea that is supported by research on human NF1 patients (Ribeiro et al., 2015).

The $n f 1$ gene encodes neurofibromin, a GTPase-activating protein that inhibits Ras-MAPK signaling. Heterozygous deletion of $n f 1$ causes disinhibition of the Ras-MAPK signaling pathway, resulting in increased GABA release (Costa et al., 2002; Cui et al., 2008; Krab et al., 2008c; Shilyansky et al., 2010). Neurofibromin also interacts with the hyperpolarization-activated cyclic nucleotide-gated channel 1 (HCN1) (Omrani et al., 2015), a voltage-gated ion channel that mediates an inward cationic current (Ih) that regulates neuronal excitability (Benarroch, 2013; Shah, 2014). Reduced neurofibromin attenuates Ih predominantly in interneurons (Omrani et al., 2015), increasing their excitability. Notably, pharmacological activation of $\mathrm{HCN}$ channels can rescue electrophysiological and spatial learning deficits in adult $n f 1^{+/-}$mice.

Despite these successes with improving learning deficits in $n f 1^{+/-}$mice, clinical trials based on these approaches for treating NF1 patients have been unsuccessful (Krab et al., 2008b; van der Vaart et al., 2013; Payne et al., 2016; Stivaros et al., 2018). Possibly, cognitive deficits in NF1 patients originate primarily in the cortex in contrast to the hippocampal origin of the spatial learning deficit in $n f 1^{+/-}$mice. While hippocampal plasticity remains high throughout life (Attardo et al., 2015), cortical plasticity becomes more restrained once critical periods of development have closed (De Paola et al., 2006). Thus, NF1 may cause deficits in cortical development that can no longer be corrected by treatment at a later age (Castrén et al., 2012). So far, NF1 clinical trials have been conducted in adults or in children that are 8 years or older, when many developmental processes are already completed.

If NF1 increases cortical inhibition during postnatal development, this may impact various stages of cortical refinement. At early stages of postnatal development, spontaneous activity of inhibitory and excitatory neurons guides neuronal connectivity (Bonifazi et al., 2009). In the primary visual cortex (V1), for example, synchronized bursts of action potentials (APs) refine topographic connections before eye opening through correlation-based plasticity mechanisms (Xu et al., 2011; Ackman et al., 2012; Lee et al., 2014; Triplett et al., 2014; Winnubst et al., 2015). Studies on ocular dominance (OD) plasticity in mouse V1 revealed that maturation of inhibitory innervation regulates the onset and closure of critical periods during which cortical connectivity is fine-tuned based on sensory inputs (Hensch et al., 1998; Fagiolini and Hensch, 2000; Hensch, 2005). Changes in inhibition during development may thus cause lifelong cognitive issues in NF1 patients.

Here we show that inhibition was increased during development of $\mathrm{V} 1$ in $n f 1^{+/-}$mice. Spontaneous neuronal activity during early development was unaffected in V1 of $n f 1^{+/-}$mice, while the critical period of OD plasticity closed prematurely. We also found that environmental enrichment during development removed the differences in inhibitory innervation and OD plasticity between $n f 1^{+/-}$mice and WT littermates. Our findings suggest that critical periods are dysregulated in NF1 and that treatment of the disorder has to start early to prevent lifelong cognitive problems.

\section{Materials and Methods}

Animals. Experimental mice were obtained by crossing $n f 1^{+/-}$mice (C57BL/6J background) with 129S2/SvHsd mice (Envigo). For all experiments, we used both male and female mice, which were on a $12 \mathrm{~h} \mathrm{light/}$ dark cycle between 0700 and $1900 \mathrm{~h}$, and fed standard laboratory food ad libitum. Mice were housed under specific pathogen-free conditions. All experiments involving mice were approved by the institutional animal care committee and conducted with permission of the animal experiment committee.

Viral injections. We used a viral vector to EGFP label inhibitory neurons in $\mathrm{V} 1$ of $n f 1^{+/-}$mice, to make it easier to perform electrophysiological recordings on fast-spiking interneurons. Pups (P0-P5) were anesthetized by hypothermia and placed in a cooled stereotact. A glass capillary (30-40 $\mu \mathrm{m}$ diameter) filled with $60 \mathrm{nl}$ of an AAV vector driving EGFP expression under the control of the mouse DLX promoter (ssAAV-1/2-mDlx-HBB-chI-EGFP-WPRE-SV40p(A), Viral Vector Facility, ETH) with a total concentration of $10^{8}$ genome $/ \mathrm{ml}$ was used for injections through the skull, into V1. Pups were placed on a heat pad before they were returned to the mother.

Slice electrophysiology. All slice electrophysiology was performed on 10- to 11-, 12- to 13-, or 27- to 32-d-old transgenic mice and agematched controls. Mice were anesthetized using isoflurane and then decapitated. For most experiments, brains were quickly removed and kept at $0^{\circ} \mathrm{C}$ in carbogenated $\left(95 \% \mathrm{O}_{2} / 5 \% \mathrm{CO}_{2}\right)$ normal ACSF containing $126 \mathrm{~mm} \mathrm{NaCl}, 3 \mathrm{~mm} \mathrm{KCl}, 1 \mathrm{~mm} \mathrm{MgSO}$, $2 \mathrm{~mm} \mathrm{CaCl}_{2}, 10 \mathrm{~mm}$ glucose, $1.20 \mathrm{~mm} \mathrm{NaH}_{2} \mathrm{PO}_{4}$, and $26 \mathrm{~mm} \mathrm{NaHCO}_{3}$ (300 mOsm and pH 7.3); 330 $\mu \mathrm{m}$-thick coronal slices containing the visual cortex were cut on a vibratome (Microm HM650V; Thermo Fisher Scientific) while keeping the slices in their slicing solution at $0^{\circ} \mathrm{C}$. After slicing, all slices were kept in normal ACFS at $35^{\circ} \mathrm{C}$ for $15 \mathrm{~min}$ for recovery, while continuously bubbled with carbogen. Next, slices were kept in continuously carbogenated ACSF at room temperature until use (1-6 h after slicing). To perform electrophysiological experiments, slices were moved to a chamber with continuous inflow and outflow of carbogenated ACSF at a rate of 1-2 $\mathrm{ml} / \mathrm{min}$ at room temperature. A glass pipette with an impedance between 3 and $4 \mathrm{~m} \Omega$ was filled with intracellular solution. Whole-cell recordings were made using a patch-clamp amplifier (Multiclamp 700a, Molecular Devices), and signals were low-pass filtered at $4 \mathrm{kHz}$ and digitized at $10 \mathrm{kHz}$ with a Digidata $1440 \mathrm{~A}$ (Molecular Devices) operated by PClamp 10 software. Care was taken that series resistance remained $\leq 15$ $\mathrm{M} \Omega$. Verification that a pyramidal neuron was selected was based on the shape of APs fired upon increasing current injection. Recordings in which the input resistance fluctuated $>20 \%$ during the experiment, indicating leakiness of the membrane and instability of the whole-cell patchclamp recording, were discarded. Before recording sIPSCs, the pipettes were filled with K-gluconate internal solution containing $70 \mathrm{~mm} \mathrm{~K}$-gluconate, $70 \mathrm{~mm} \mathrm{KCl}$, $0.5 \mathrm{~mm}$ EGTA, $10 \mathrm{~mm}$ HEPES, 4 mм Mg-ATP, $4 \mathrm{~mm}$ K2 phosphocreatine, and $0.4 \mathrm{~mm}$ GTP (pH 7.3 and $290 \mathrm{mOsm}$ ). Here, the AMPA receptor blocker DNQX (Ascent Scientific), was applied in the extracellular solution $(10 \mu \mathrm{M})$. For all experiments, cells were clamped at $-70 \mathrm{mV}$ and sIPSCs were measured during $10 \mathrm{~min}$. Mini Analysis (Synaptosoft) was used for analyzing sIPSCs.

For recording the excitability of fast-spiking interneurons, slices were cut in ice-cold carbogenated cutting ACSF $125 \mathrm{~mm} \mathrm{NaCl}, 3 \mathrm{~mm} \mathrm{KCl}, 6$ mм $\mathrm{MgCl}_{2}, 1 \mathrm{~mm} \mathrm{CaCl}_{2}, 25 \mathrm{~mm}$ glucose, $1.25 \mathrm{~mm} \mathrm{NaH}_{2} \mathrm{PO}_{4}, 1 \mathrm{~mm}$ kynurenic acid, and $25 \mathrm{~mm} \mathrm{NaHCO}_{3}$. Slices were kept in carbogenated $\mathrm{ACSF}$ at $35^{\circ} \mathrm{C}$ for $35 \mathrm{~min}$ to recover and then allowed to return to room temperature for $30 \mathrm{~min}$ before starting experiments. To perform electrophysiological experiments, slices were moved to a chamber with continuous inflow and outflow of carbogenated ACSF at a rate of $1-2 \mathrm{ml} / \mathrm{min}$ at room temperature. Glass pipettes with an impedance of $\sim 8 \mathrm{M} \Omega$ were used, filled with K-gluconate internal solution containing $5 \mathrm{mg} / \mathrm{ml}$ biocytin (Sigma-Aldrich, B4261). Interneurons were recognized by a round soma and the absence of a clear apical dendrite. Only interneurons with a fast-spiking firing pattern were included in the analysis. Whole-cell recordings were made using a patch-clamp amplifier (Multiclamp 700b, Molecular Devices) operated by AxoGraph software.

Two-photon calcium imaging. Mice from postnatal day (P) 10-12 were used to study activity patterns in the developing visual cortex in 
vivo, as previously described (Siegel et al., 2012). In brief, the animals were anesthetized with isoflurane $\left(2 \%\right.$ in $\left.1.7 \mathrm{~L} / \mathrm{min}_{2}\right)$ and after anesthesia had become effective, lidocaine $(0.5 \mathrm{mg} / \mathrm{g}$ body weight, Astra Zeneca) was injected into the neck muscle. The animal was then transferred to the imaging setup and placed on a heating blanket $\left(35.5^{\circ} \mathrm{C}\right)$. A head bar with an opening (Ø $4 \mathrm{~mm}$ ) above the visual cortex $(0.5-2.5$ $\mathrm{mm}$ rostral from $\lambda$ and 1-3 mm lateral from the midline) was attached to the skull and a small craniotomy above the visual cortex was performed without perforating the dura. The exposed cortical surface was kept moist with cortex buffer. The multicell bolus loading technique (Stosiek et al., 2003) was used to stain large populations of cells with the calcium-sensitive dye Oregon Green 488 BAPTA-1 AM (OGB-1, Invitrogen). For calcium imaging, isoflurane levels were lowered to $0.7 \%-1 \%$. Calcium dynamics were monitored with a two-photon microscope (Movable Objective Microscope, Sutter Instrument) and a modelocked Ti:Sapphire laser (Spectra Physics, $\lambda=810 \mathrm{~nm}$ ). To monitor spontaneous network activity over time, consecutive xyt-stacks with a frame rate of 5 or $7.5 \mathrm{~Hz}$ were acquired through a $40 \times$ water-immersion objective (0.8 NA, Olympus), controlled by Labview (National Instruments)-based software.

Calcium data analysis. Data analysis recordings of spontaneous network activity were analyzed with custom-written algorithms in ImageJ (National Institutes of Health) and MATLAB (The MathWorks) (Winnubst et al., 2015). The image stacks were preprocessed by removing frames containing large-movement artifacts and aligned using Turboreg with ImageJ or Normcorre (Pnevmatikakis and Giovannucci, 2017) with MATLAB. After preprocessing, contours of the cells were drawn using ImageJ by creating a mask after auto local thresholding. Glial cells in the FOV showed elevated basal intensity and were not active. Therefore, all included ROIs were neuronal. The stacks were then fed into MATLAB codes designed by Winnubst et al. (2015) to automatically calculate $\Delta \mathrm{F} / \mathrm{F} 0$ traces, representing changes in intracellular calcium concentration. Next, the $\Delta \mathrm{F} / \mathrm{F} 0$ traces were used to detect activity events of individual cells. To reliably determine activity events, both the $\Delta \mathrm{F} / \mathrm{F} 0$ trace and its derivative were used for signal detection. The signal detection threshold was adjusted separately for each experiment (1-4 times the $\mathrm{SD}$ above the $\Delta \mathrm{F} / \mathrm{F} 0$ and derivative traces) but remained the same for all recordings within an experiment. We found that the relationship between signal and noise differed between experiments for various reasons, including differences in dye loading and fixation of the preparation, which required adapting the thresholds to optimize signal detection for each experiment. The frame in which both traces reached the threshold was considered to represent an activity event of an individual cell. A network event was defined as the activity in all cells that were active within consecutive frames that were not separated by two or more frames during which no activity was recorded. The participation rate was determined by the total number of active neurons during one network event over the total number of detected neurons in the FOV. Activity was scored when at least $6 \%$ of the imaged cells reached threshold, whereas a network event was defined by a minimum participation rate of $>20 \%$. The mean peak amplitude of the calcium signal of individual coactive cells was calculated by averaging the maximum $\Delta \mathrm{F} / \mathrm{F} 0$ value of all active cells during a network event. Previously, we found that two types of activity occur in the visual cortex at this developmental age: Levents are low participation (20\%-80\%) and low-amplitude events that are generated in the retina and transmitted to the cortex, whereas $\mathrm{H}$ events are high participation $(>80 \%)$ and high-amplitude events that are generated within the cortex (Siegel et al., 2012). Here we also divided the data into $\mathrm{H}$ - events and $\mathrm{L}$ - events based on participation $(>80 \%$ or $<80 \%$ ). The frequency of $\mathrm{L}$ - events and $\mathrm{H}$ - events was determined by dividing the total number of recorded events in each category by the recording duration. Event amplitudes were calculated by averaging the maximum $\Delta \mathrm{F} / \mathrm{F} 0$ value of all active cells for each event type.

Immunohistochemistry. Age-matched mice were anesthetized with $0.1 \mathrm{ml} / \mathrm{g}$ body weight Nembutal (Janssen) and perfused with 4\% PFA in PBS ( $\sim 80 \mathrm{ml}$ per mouse) and postfixed for $2-6 \mathrm{~h}$. Postfixation time was consistent between compared groups. V1 coronal sections of $50 \mu \mathrm{m}$ were made by using a vibratome (Leica Microsystems, VT1000S). Biotinylated Wisteria Floribunda agglutinin (WFA, 1:500, Vector Laboratories,
B-1355) together with mouse- $\alpha$-parvalbumin (PV, 1:500, Swant, PV235) was used to label perineuronal nets $(\mathrm{PNN})$ and $\mathrm{PV}^{+}$interneurons. Mouse- $\alpha$-synaptotagmin-2 (1:1000, ZFIN, ZDB-ATB-081002-25), together with rabbit- $\alpha$-neuronal nuclei (1:1000, Millipore, MABN140), was used to label $\mathrm{PV}^{+}$boutons and neuronal soma. Primary antibodies/ WFA were visualized using AlexaFluor-594 conjugated to streptavidin (1:500, Invitrogen, S32356), AlexaFluor-488 goat- $\alpha$-mouse (1:500, Invitrogen, A28175), AlexaFluor-568 goat- $\alpha$-mouse (1:1000, Invitrogen, A11004), and AlexaFluor-488 goat- $\alpha$-rabbit (1:1000, Invitrogen, A11070). All antibodies were previously tested in mice for the application we used them for (more information can be found in the references or on the websites of the suppliers). Free-floating sections were briefly washed in PBS followed by $1-2 \mathrm{~h}$ blocking in PBS containing 5\% normal goat serum and $0.1 \%$ Triton X-100 at room temperature. Primary antibody incubation was performed overnight at $4^{\circ} \mathrm{C}$ in fresh blocking solution. Next, the sections were washed 3 times for $10 \mathrm{~min}$ in PBS with $0.1 \%$ Tween-20 (PBST) followed by secondary antibody incubation in fresh blocking solution for $1.5-2 \mathrm{~h}$ at room temperature. After washing 3 times for $10 \mathrm{~min}$ in TBST, the sections were mounted on glass slides using Mowiol (Calbiochem/MerckMillipore), glass covered, and stored at $4^{\circ} \mathrm{C}$.

To confirm that patched (biocytin-filled) interneurons were $\mathrm{PV}^{+}$ interneurons, acute slices were directly placed into 4\% PFA in PBS for 20-25 min followed by three $10 \mathrm{~min}$ washes in PBS. Next, tissue was blocked for $2 \mathrm{~h}$ in PBS containing 2\% Triton-X, 5\% BSA, and 5\% normal goat serum. Primary antibody against PV (rabbit- $\alpha$-PV, Swant, PV27, 1:500) was diluted in blocking buffer and incubated for two nights at room temperature. Following three 10 min washes in PBS, AlexaFluor555 goat- $\alpha$-rabbit (Thermo Fisher Scientific, A27039) and AlexaFluor633 streptavidin (Invitrogen, S32364), both 1:500 in PBS were incubated for $2 \mathrm{~h}$. The tissue was finally washed in PBS 3 times for $10 \mathrm{~min}$ before mounting using FluorSave mounting medium (Merck-Millipore, \#345789).

Confocal microscopy and data analysis. Sections were imaged using a confocal microscope (Leica Microsystems, SP5) with constant gain and laser power across compared samples. Care was taken that no signal clipping was present. For quantification of perisomatic puncta formed by $\mathrm{PV}^{+}$interneurons, images were made using a $40 \times$ objective at a resolution of $1024 \times 1024$ pixels. Fluorescent puncta were analyzed using a noncommercially available macro for Image-Pro PLUS (version 6.3). Up to 6 puncta rings per image obtained from V1 sections were manually encircled after which a mask was created on the cell. A 2- $\mu \mathrm{m}$-wide ring was calculated around the mask, and all puncta in the ring were considered to belong to the cell and were counted and measured. Signals not reaching size and fluorescent threshold levels were omitted, as previously described (Sommeijer and Levelt, 2012). Pixel intensity for the signal within masks was considered background and subtracted from the intensity values in the puncta.

To determine the distribution of interneurons that stained positive for PV, images were made using a $10 \times$ objective at a resolution of $1024 \times 1024$ pixels. Maximum projections were made of $z$ stacks of seven steps. V1 was cropped, and layering was estimated based on cortical thickness. Trainable Weka Segmentation (Arganda-Carreras et al., 2017), an ImageJ plugin, was used to train a classifier (Out-Of-Bag error $<5 \%$, training data from both genotype) to define ROIs representing $\mathrm{PV}^{+}$interneurons. The resulting segmentation, manually curated, was used to determine the number of $\mathrm{PV}^{+}$interneurons per $\mathrm{mm}^{2}$ across $\mathrm{V} 1$ and the fraction of $\mathrm{PV}^{+}$interneurons per layer.

$z$ stacks that were imaged with a $20 \times$ objective $(1024 \times 1024$ resolution) were processed in a similar way to identify ROIs representing $\mathrm{PV}^{+}$ interneurons. Background fluorescence was corrected for by subtracting the mean fluorescent intensity of a small region surrounding the $\mathrm{PV}^{+}$ cell from the signal. Subsequently, the average intensity of $\mathrm{PV}^{+}$interneurons in layer $2 / 3,4$, or 5 was determined for each mouse and normalized by dividing the value by the average intensity in layer 4 of $\mathrm{V} 1$ of the group of age-matched WT mice.

The previously selected ROIs were used to assess the WFA intensity in the PNNs around the $\mathrm{PV}^{+}$interneurons. Again, Trainable Weka Segmentation was used to train a classifier model for PNNs (Out-Of-Bag 
error $<5 \%$ ). This model was used to check a small area surrounding the PV ROIs for the presence of possible PNNs. The contrast in these regions was boosted using contrast limited adaptive histogram equalization to increase the sensitivity of the model. The resulting segmentation was used to assess the intensity (at original contrast) of the PNN, if present. This value was corrected for background staining by subtracting the mean of a small area surrounding the PNN. Subsequently, the average PNN intensity and the fraction of $\mathrm{PV}^{+}$interneurons enwrapped by a PNN were determined for layers $2 / 3,4$, and 5 . The average intensity in layer 4 across age-matched WT mice was used for normalization.

Environmental enrichment. For enriched environment housing, commercially available cages (Marlau) were used (Fares et al., 2012). Pregnant mothers were placed in a Marlau cage. Its ground floor houses a running wheel and a shelter and comprises two compartments: one with food and one with water. Moving from one compartment to the other can only be achieved through the upper floor in which a maze is placed that is regularly changed. Pups were reared in this environment until the time of the experimental measurement.

Surgical preparation. For monocular deprivation (MD), the upper and lower lids of the right eye were clipped and sutured together with two mattress sutures during isoflurane anesthesia. During the procedure, the eye was rinsed with saline and after suturing lidocaine cream was applied to the closed eyelid. At the start of an imaging session, the eyes were reopened. Animals that had premature opening of the eye or a damaged eye were excluded from the experiments.

Optical imaging and visual stimulation. For optical imaging of intrinsic signal, mice were anesthetized with an intraperitoneal injection of urethane (Sigma Millipore; $20 \%$ solution in saline, $2 \mathrm{mg} / 10 \mathrm{~g}$ body weight). This was immediately followed by a subcutaneous injection of atropine sulfate $(50 \mu \mathrm{g} / \mathrm{ml}$ in saline, $1 \mu \mathrm{g} / 10 \mathrm{~g}$ body weight) to reduce excretions from mucous membranes and chlorprothixene (Sigma Millipore; $2 \mathrm{mg} / \mathrm{ml}$ in saline, $80 \mu \mathrm{g} / 10 \mathrm{~g}$ body weight). Sometimes a supplement of urethane of $\sim 10 \%$ of the initial dose was necessary to obtain a sufficient depth of anesthesia. Anesthetized mice were placed on a heating pad, and body temperature was monitored with a rectal probe and maintained at $36.5^{\circ} \mathrm{C}$. A continuous flow of oxygen was provided close to the nose. The mouse was fixated by ear bars with conical tips and a bite rod behind the front teeth, $3 \mathrm{~mm}$ lower than the ear bars. The scalp was treated with xylocaine (lidocaine $\mathrm{HCl}$, atropine sulfate), and part of the scalp was removed to expose the skull. The skull was cleaned using saline. Black cloth was used to prevent light from the monitor reaching the camera. Settings for retinotopy and OD measurements were as previously described (Heimel et al., 2007). Briefly, the exposed skull was illuminated with $700 \mathrm{~nm}$ light. Responses were acquired with an Optical Imager 3001 system (www.opt-imaging.com). A 21 inch $\gamma$-corrected monitor placed $15 \mathrm{~cm}$ in front of the mouse covering the visual field was divided in $2 \times 2$ square patches. The retinotopic map was assessed by full-contrast square-wave $0.05 \mathrm{cpd}$ gratings of changing orientation, which were shown in one of four quadrants while the adjoining screen was gray and of the same average intensity. Ten to 15 stimuli in each quadrant were sufficient to construct a retinotopic map of V1. The retinotopic representation of the upper nasal patch was used to calculate responses for OD experiments. Computer impulse-operated shutters were placed in front of both eyes. Shutters opened in preset intervals, and the stimulus sequence described above was presented. Shutters opened $9 \mathrm{~s}$ before stimulus onset and stayed open during the entire acquisition period, 50 responses to each eye were recorded. The imaged OD index is defined as the iODI $=$ (contralateral response - ipsilateral response)/(contralateral response + ipsilateral response). For all quantitative measurements, an alternative normalization procedure was used. An ROI polygon was drawn in the retinotopic map around all pixels assigned to the upper medial quadrant of the screen. The small size of the mouse visual cortex allowed imaging some cortical area outside of primary visual cortex. From this area, a larger region of reference was selected where no stimulus response, blood vessel artifact, or irregularities of the skull were observed in the retinotopic map. Normalization was conducted by taking the negative ratio of ROI over region of reference signal, normalizing it to stimulus onset and averaging the signal from one frame after stimulus onset to $2 \mathrm{~s}$ after stimulus offset. The average of this ratio over all stimulus presentations was used as response measure.

Statistics. We determined whether all data were normally distributed using the Shapiro-Wilk test. For testing differences in multiple criteria, such as genotype and age or genotype and treatment, we computed whether there was a significant interaction in a two-way ANOVA. For graphical representation of significant differences between groups, we presented the results of post hoc Tukey-Kramer tests, unless stated otherwise. When two independent groups were compared, we used $t$ test if the data were normally distributed (Shapiro-Wilk test). Otherwise, a Mann-Whitney test was used.

\section{Results}

Inhibition increased in $n \mathrm{fl}^{+/-}$mice after eye opening We first wanted to understand whether, in $n f 1^{+/-}$mice, changes in inhibitory innervation occurred that might affect cortical development. We started by analyzing whether inhibitory inputs in V1 neurons of these mice were altered before eye opening at P10 or just after at P12. We used patch-clamp recordings in slices of $\mathrm{V} 1$ from $n \mathrm{fl}^{+/-}$mice and littermate controls and measured the frequency and amplitudes of sIPSCs in layer $2 / 3$ pyramidal neurons. We found that, right after eye opening, the sIPSC frequency increased strongly in $n f 1^{+/-}$mice but only showed an upward trend in WT mice (Fig. 1A-D). The sIPSC amplitudes did not alter after eye opening and did not differ between genotypes (Fig. $1 C, D)$. We conclude that, after eye opening, but not before, pyramidal neurons in $n f 1^{+/-}$mice receive more inhibitory inputs than those in control littermates.

\section{Unaltered spontaneous activity patterns in $n f 1^{+/-}$mice}

To test whether this increase in inhibitory inputs of pyramidal cells in $n f 1^{+/-}$mice affected cortical activity patterns, we used in vivo calcium imaging to investigate intrinsically generated spontaneous waves of activity that drive early cortical development (Siegel et al., 2012; Leighton and Lohmann, 2016). It was previously shown that, in the developing visual system, two types of network activity can be identified. One type is cortex derived and characterized by high participation $\left(\mathrm{H}_{-}\right)$events in which $>80 \%$ of neurons are synchronously active. The other type originates largely in the retina and is characterized by low participation (L-) events, in which $20-80 \%$ of the cortical neurons are synchronously active (Mooney et al., 1996; Siegel et al., 2012). As these spontaneous activity patterns are thought to be coordinated by the interaction of inhibitory and excitatory neurons, we wanted to understand whether $\mathrm{L}$ - or $\mathrm{H}$ - events were altered in $n f 1^{+/-}$ mice. Using two-photon calcium imaging, we assessed the spontaneous cortical activity in $n f 1^{+/-}$mice and control littermates that were 10 or $12 \mathrm{~d}$ of age (Fig. $2 A, B$ ). These experiments revealed that the frequency of all events was not significantly altered, although it appeared to be slightly higher in $n f 1^{+/-}$mice (Fig. 2C). Previously, we found that, in a mouse model of Fragile-X, the percentage of $\mathrm{L}$ - events was the best indicator for altered network activity (Cheyne et al., 2019). The percentage of $\mathrm{L}-$ events in $n f 1^{+/-}$mice was unchanged, however (Fig. $2 D$ ). Neither did we detect a difference in mean amplitude over all coactive cells during network events (Fig. 2E,F). Thus, the altered levels of inhibitory inputs of layer $2 / 3$ pyramidal neurons of V1 do not significantly affect their activity patterns during spontaneous network activity in $n f 1^{+/-}$mice.

\section{Increased inhibitory currents in excitatory neurons in $\mathrm{V} 1$ of $n f 1^{+/-}$mice during the critical period}

An increase in the inhibition/excitation ratio regulates the onset and closure of the critical period of OD plasticity in V1, during 
A

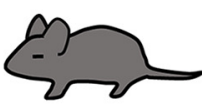

P10-11

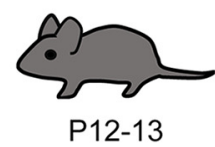

sIPSC P10-11

wt

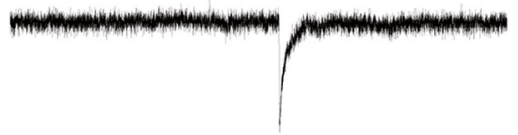

$n f 1^{+1}$

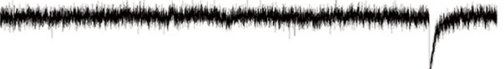

C

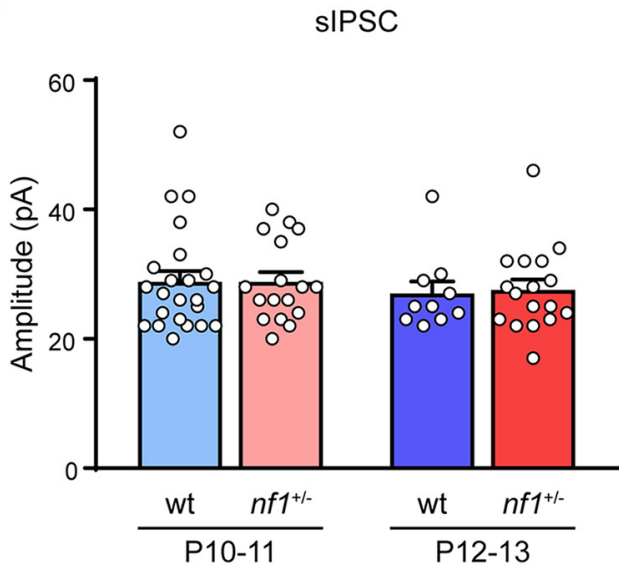

D

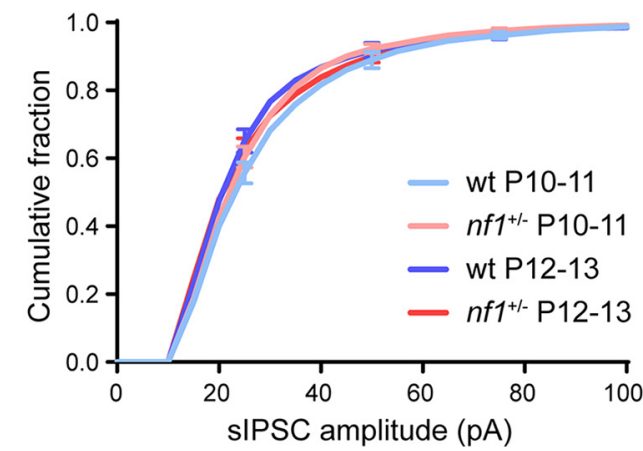

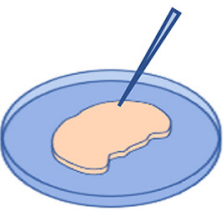

sIPSC P12-13

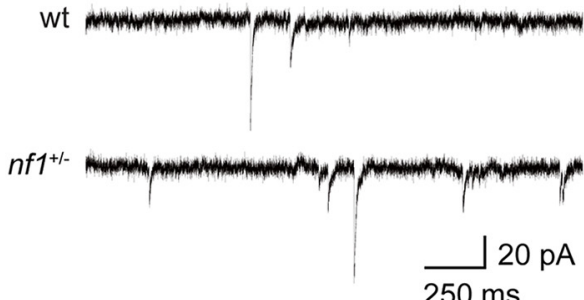

$250 \mathrm{~ms}$

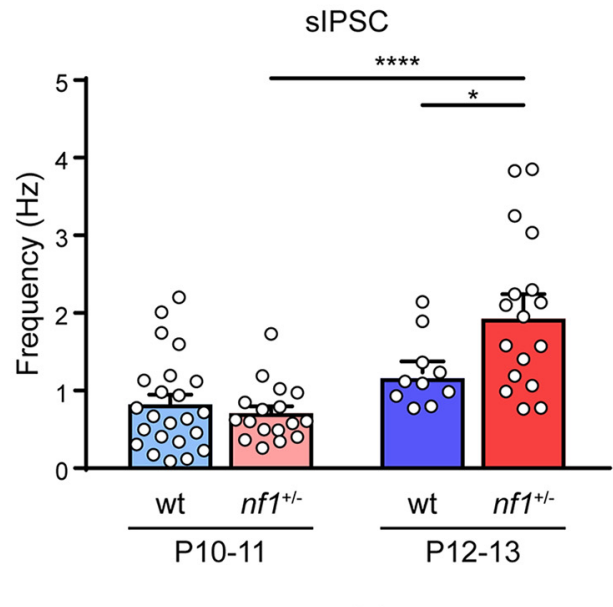

SIPSC

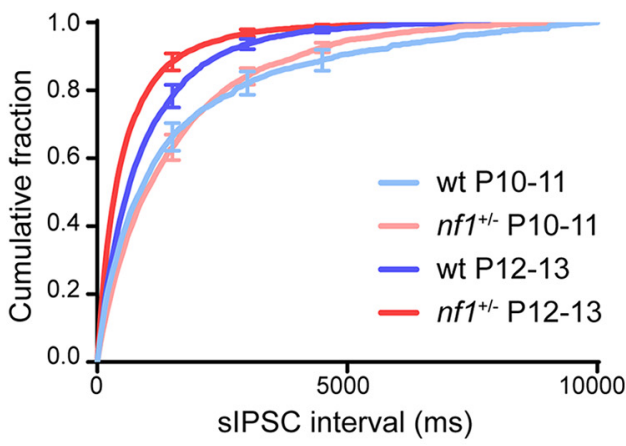

Figure 1. Rapid increase in inhibition after eye opening in $n 1^{+/-}$mice. $A$, Schematic illustration of the experimental approach. Electrophysiological recordings are performed in layer $2 / 3$ of V1 in mice before and after eye opening at P10-P11 and P12-P13. B, Representative traces of sIPSCS in WT and $n f 1^{+/-}$mice before and after eye opening at P10-P11 and P12-P13. C, Average amplitude and frequency of sIPSCS. The frequency of sIPSCs increases significantly faster in $n f 1^{+/-}$mice, compared with WT mice: two-way ANOVA, $F_{(1,63)}=6.72, p=0.01, p 0 s t$ hoc Tukey's, WT: P10-P11 ( $n=23$ cells from 9 mice) versus P12-P13 ( $n=10$ cells from 4 mice), $p=0.55, n f 1^{+/-}$: P10-P11 ( $n=17$ cells from 5 mice) versus P12-P13 ( $n=17$ cells from 5 mice), $p<0.0001$, P12-P13: WT versus $n f 1^{+/-}, p=0.03$, whereas the amplitude remains unchanged (two-way ANOVA, $\left.F_{(1,63)}=0.028, p=0.87\right)$. D, Cumulative distributions of sIPSC amplitudes and interevent intervals in P10-P11 and P12-P13 mice. ${ }^{*} p<0.05,{ }^{* * * *} p<0.0001$.

which visual experience refines the synaptic connectivity. We therefore tested whether cortical inhibition was also increased in $n f 1^{+/-}$mice during the peak of the critical period of OD plasticity using patch-clamp recordings in slices of V1 from P28 $\mathrm{nfl}^{+/-}$ mice and WT littermates. These experiments confirmed, also at this age, that sIPSCs occurred significantly more frequently in layer $2 / 3$ pyramidal neurons of $n f 1^{+/-}$animals compared with their WT littermates (Fig. $3 A-D$ ). Similarly to the situation at
P12, the sIPSC amplitudes (Fig. $3 A-D$ ) were not different between $n f 1^{+/-}$and WT mice. Thus, levels of inhibition remain increased in $n f 1^{+/-}$animals during the critical period of OD plasticity in V1.

To understand whether the changes in sIPSC frequency were caused by changes in the level of synaptic release or synapse numbers, we also recorded mIPSCs after silencing general network activity with the sodium blocker TTX. We found that 
A

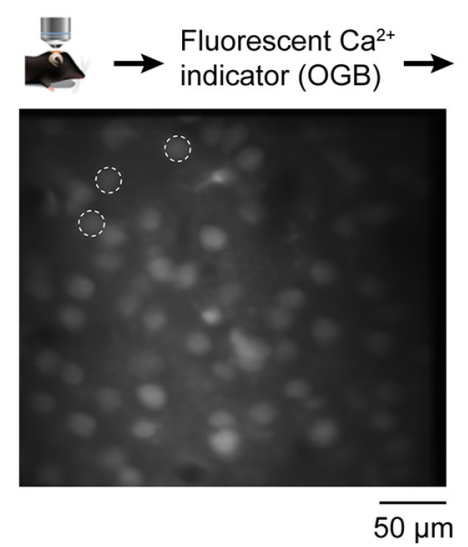

B

cell 1

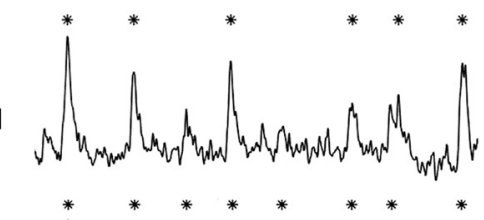

cell 2

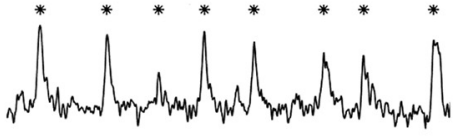

cell 3

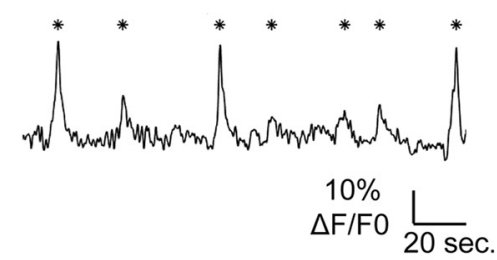

C

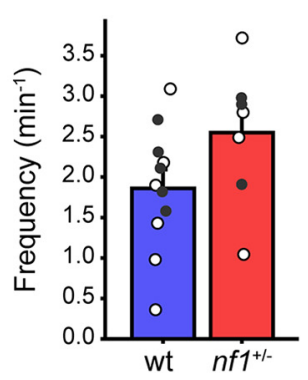

D

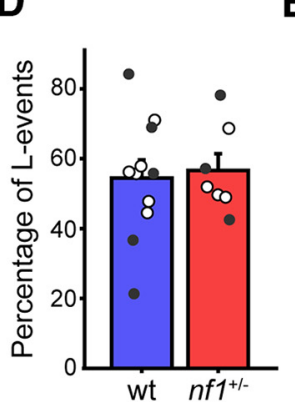

E

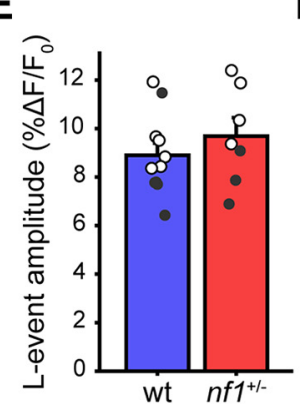

F

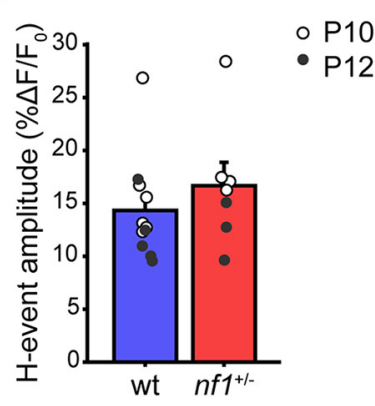

Figure 2. Normal early postnatal cortical development in $n f 1^{+/-}$mice. $A, A$ schematic illustration of the in vivo two-photon calcium imaging experimental setup and an image of layer $2 / 3$ cells in the visual cortex of a P10 animal labeled with OGB-1. B, Example traces of spontaneous network dynamics in neurons indicated on the left. *Detected network events. L- and H- events were determined based on the participation of multiple cells during a $1 \mathrm{~h}$ recording. Participation $>80 \%$ is $\mathrm{H}$ - event, and participation between $20 \%$ and $80 \%$ is an $\mathrm{L}$ - event. $\mathbf{C}$, Frequencies of all events are unaltered in $n f 1^{+/-}$mice compared with WT ( $t$ test, $p=0.10$, WT: $n=11$ mice, $n f 1^{+/-}: n=7$ mice). $\boldsymbol{D}$, Percentage of $\mathrm{L}-$ events is unchanged in $n f 1^{+/-}$mice ( $\left.p=0.78\right)$. $\boldsymbol{E}$, Mean cellular amplitudes of $\mathrm{L}$ - events are unchanged ( $t$ test, $p=0.38)$. $\boldsymbol{F}$, Also the mean cellular amplitudes of $\mathrm{H}$ - events are unchanged $(t$ test, $p=0.37)$.

mIPSC frequencies were unaltered in $n f 1^{+/-}$mice (Fig. $3 E, F$ ), suggesting that the increase in sIPSCs was not due to increased vesicle release or synapse numbers. It therefore appeared more likely that the increase in sIPSC frequency was due to increased excitability of inhibitory neurons in $n f 1^{+/-}$mice, in line with previous findings (Omrani et al., 2015).

\section{Excitability of inhibitory neurons is selectively increased}

To test whether parvalbumin-expressing $\left(\mathrm{PV}^{+}\right)$interneurons were more excitable in $n f 1^{+/-}$mice, we performed whole-cell recordings in fast-spiking interneurons and assessed the number of APs evoked by current injection. We focused on fast-spiking interneurons as these mostly represent $\mathrm{PV}^{+}$basket cells, which have been shown to be the main source of inhibition regulating critical period onset and closure (del Rio et al., 1994; Chattopadhyaya et al., 2004; Sugiyama et al., 2008; Kuhlman et al., 2013). To assist the identification of these neurons, we made use of mice in which a viral vector was injected in V1 driving interneuron-specific EGFP expression. Immunohistochemical assessment of several recorded neurons confirmed that fast-spiking neurons represented $\mathrm{PV}^{+}$interneurons (Fig. 4A). We found that, upon current injection, fast-spiking interneurons in slices from $n f 1^{+/-}$mice fired more APs than those in in slices from WT littermates (Fig. 4B,C). Resting membrane potential (-62.07 $\pm 0.65 \mathrm{vs}-63.36 \pm 1.07 \mathrm{mV})$, input resistance $(145.5 \pm 20.28 \mathrm{vs}$ $99.40 \pm 21.90 \mathrm{MOhm})$, rheobase $(163.6 \pm 23.44$ vs $202 \pm$ $35.05 \mathrm{pA})$, AP threshold $(37.95 \pm 1.03$ vs $37.59 \pm 0.60 \mathrm{mV})$, AP amplitude $(83.96 \pm 0.934$ vs $84.62 \pm 1.62 \mathrm{mV})$, AP half-width $(0.3861 \pm 0.02$ vs $0.3745 \pm 0.02 \mathrm{~ms})$, and percentage sag $(8.133$ $\pm 1.14 \%$ vs $8.101 \pm 1.35 \%)$ were all unchanged. We assessed whether the excitability of layer $2 / 3$ pyramidal neurons was also higher in $n f 1^{+/-}$compared with WT mice at this age. This was not the case, and no difference in the maximal number of APs fired could be detected between $n f 1^{+/-}$mice and their WT littermates (Fig. 4D,E). Thus, these results confirm that the levels of inhibition were higher at the peak of the critical period in $n f 1^{+/-}$ mice than in control littermates, due to a selective increase in the excitability of inhibitory neurons.

\section{No change in size and density of boutons formed by $\mathrm{PV}^{+}$ neurons}

The absence of any difference in MIPSC frequency and amplitude between in $n f 1^{+/-}$and WT mice suggested that the numbers and sizes of inhibitory boutons in V1 would probably be unaltered in V1 of $n f 1^{+/-}$mice. To test this more directly, we focused on the inhibitory boutons formed by $\mathrm{PV}^{+}$interneurons. $\mathrm{PV}^{+}$interneurons are known to express high levels of HCN1, and their excitability was found to be increased in the hippocampus of $n f 1^{+/-}$mice (Omrani et al., 2015). We investigated whether the numbers or sizes of inhibitory boutons formed by $\mathrm{PV}^{+}$interneurons onto pyramidal neurons in layer $2 / 3$ and layer 5 were altered in $n f 1^{+/-}$mice. To this aim, we stained V1 sections of $n f 1^{+/-}$mice and WT littermates with antibodies to synaptotagmin-2, a protein selectively expressed by $\mathrm{PV}^{+}$boutons 
A

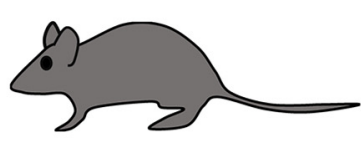

P28

B

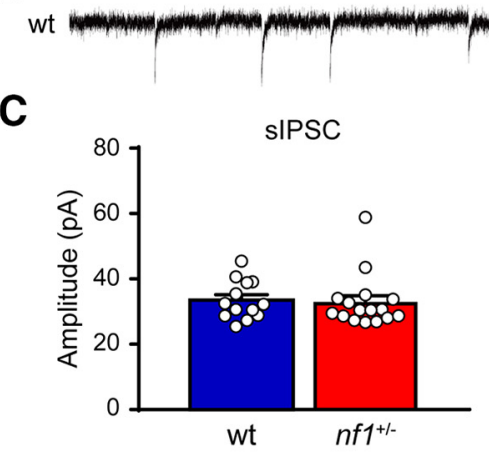

D

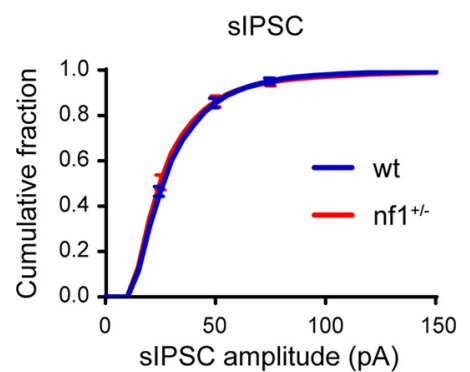

$\mathbf{E}$

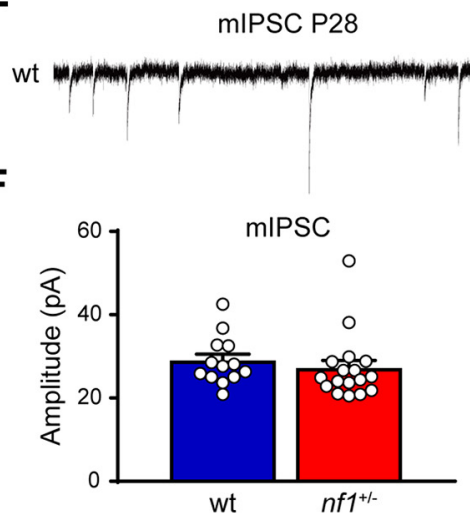

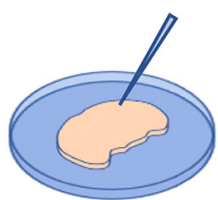

SIPSC P28
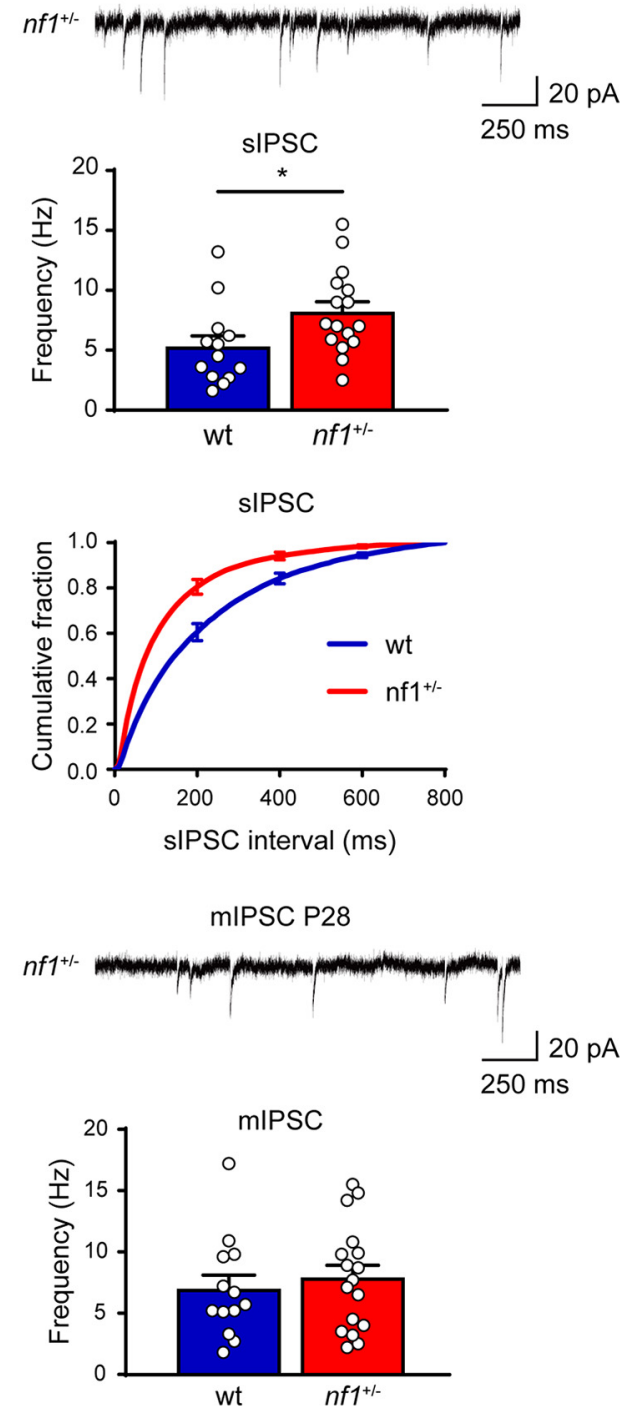

Figure 3. Enhanced inhibition in $\mathrm{L} 2 / 3$ of $\mathrm{V} 1$ in $n f 1^{+/-}$mice during the critical period. $A$, Schematic illustration of the experimental approach. Electrophysiological recordings are performed in layer $2 / 3$ of $\mathrm{V} 1$ in mice before and after eye opening around P28. B, Representative traces of sIPSC in L2/3 of V1 in 4-week-old WT and $n f 1^{+/-}$mice. $C$, Averages of sIPSC amplitude and frequency. Although sIPSC amplitude is unchanged (Mann-Whitney, $p=0.40$; WT: $n=13$ cells from 5 mice, $n f 1^{+/-}$: $n=16$ cells from 6 mice), sIPSC frequency is significantly increased in $n f 1^{+l-}$ compared with WT pyramidal neurons ( $t$ test, $p=0.03)$. D, Cumulative distributions of $\operatorname{sIPSC}$ amplitude and interevent interval. $\boldsymbol{E}$, Representative traces of mIPSCs in WT and $n f 1^{+/-}$mice at P28. $F$, Average amplitude and frequency of mIPSCs remain the same in P28 $\mathrm{nf}^{+/-}$ and WT mice (amplitude: Mann-Whitney: $p=0.19$; frequency: $t$ test: $p=0.56$; WT: $n=13$ cells from 5 mice; $n f 1^{+/-}$: $n=17$ cells from 6 mice). ${ }^{*} p<0.05$.

(Sommeijer and Levelt, 2012). Using confocal microscopy, we assessed the density and size of synaptotagmin-2 puncta around the onset, peak, and closure of the critical period (P21, P28, and $\mathrm{P} 35)$. We did not detect a difference in the density or size of perisomatic synaptotagmin- 2 puncta in layer $2 / 3$ or 5 in $n f 1^{+/-}$mice compared with WT mice (Fig. $5 A-C$ ). These data show that increased inhibitory currents are not due to increased numbers or sizes of presynaptic boutons formed by $\mathrm{PV}^{+}$interneurons.
Development of $\mathrm{PV}^{+}$interneurons in V1 not significantly altered Next, we investigated whether the increased activity of inhibitory interneurons in V1 caused an acceleration or delay in their development. To this aim, we used immunohistochemistry to assess two markers of $\mathrm{PV}^{+}$interneuron maturation: expression levels of PV and the presence of PNNs around $\mathrm{PV}^{+}$cells (visualized by WFA). We found no difference in the numbers of $\mathrm{PV}^{+}$interneurons in $\mathrm{V} 1$ of $n f 1^{+/-}$ mice and littermate controls (Fig. 6A$C$ ), and no difference in the distribution of these cells across the different cortical layers (Extended Data Fig. 6-1A), around the onset (P21-P22) and the peak (P29) of the critical period. We assessed the intensity of WFA staining per $\mathrm{PV}^{+}$interneuron (Fig. $6 D$; Extended Data Fig. 6-1). While it appeared slightly lower in $n \mathrm{fl}^{+/-}$mice at P21-P22, this difference was not significant. At P29, no difference in WFA expression was observed. Although PV expression appeared somewhat lower in P21-P22 $n f 1^{+/-}$mice, the difference was not significant (Fig. 6E; Extended Data Fig. 61). No difference was observed at P29. Finally, we quantified the fraction of $\mathrm{PV}^{+}$interneurons that were enwrapped in PNNs (Fig. 6F) and did not detect any differences between $n \mathrm{fl}^{+/-}$mice and littermate controls in any of the layers of V1 (Extended Data Fig. 6-1D). It thus appears that, while $\mathrm{PV}^{+}$interneurons are more excitable in $n f 1^{+/-}$ mice, this does not affect their maturation.

Precocious closure of the critical period of plasticity in $\mathrm{V} 1$ of $n f 1^{+/-}$ mice

Because the patch-clamp recordings revealed that inhibitory inputs were increased in $n \mathrm{nf}^{+/-}$mice during the peak of the critical period, we wanted to test whether this caused any changes in OD plasticity. To this end, we used optical imaging of intrinsic signal to determine the OD in $\mathrm{V} 1$ of $n f 1^{+\prime-}$ and WT littermates that were monocularly deprived for $3 \mathrm{~d}$ from P28 to P31, and in mice that were not deprived. We found that $3 \mathrm{~d}$ of MD caused a significant reduction of $\mathrm{V} 1$ responses to the deprived eye (Fig. $7 A-C$ ), resulting in a shift in OD toward the nondeprived eye in WT mice but not in $n \mathrm{nI}^{+/-}$mice (Fig. $7 D$ ). This indicated that $n \mathrm{fl}^{+/-}$mice show reduced OD plasticity during the peak of the critical period compared with WT control mice.

This finding may indicate that cortical plasticity is reduced in $n \mathrm{fl}^{+/-}$mice, or that the critical period for OD plasticity closes 
A

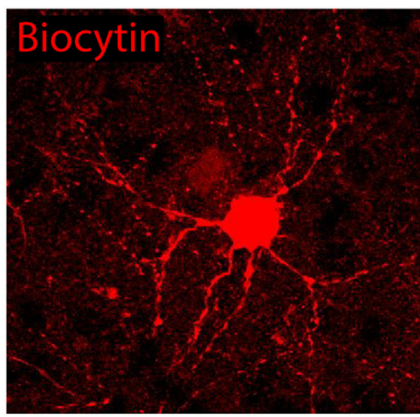

B

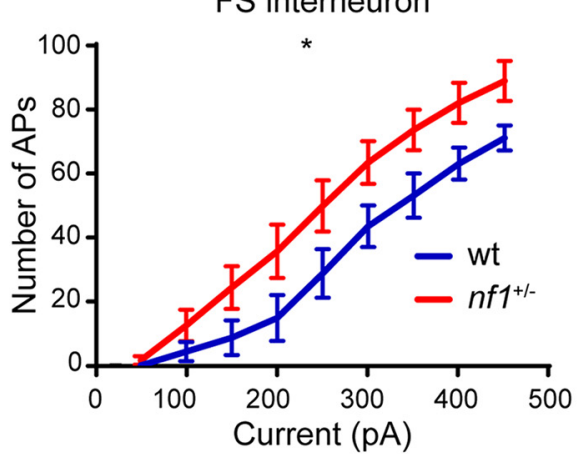

D

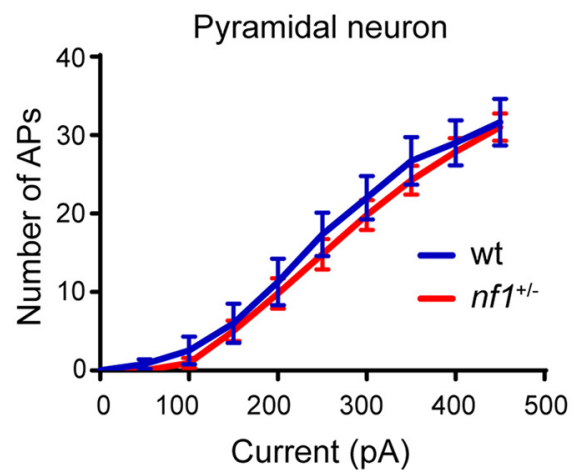

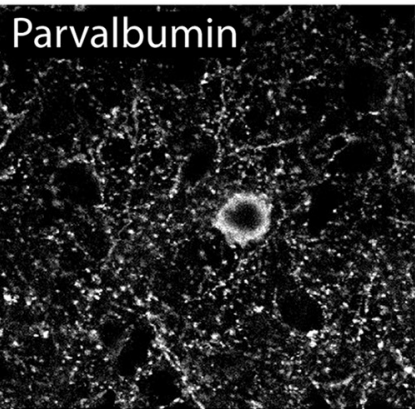

C

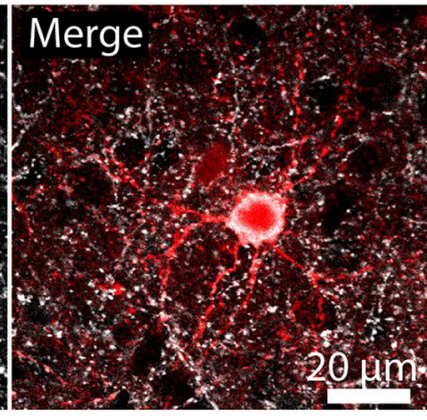

FS interneuron

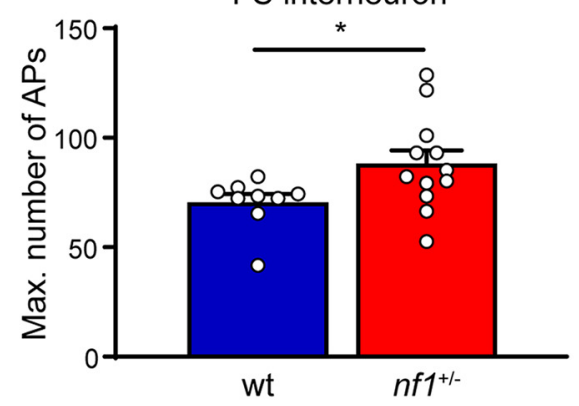

$\mathbf{E}$

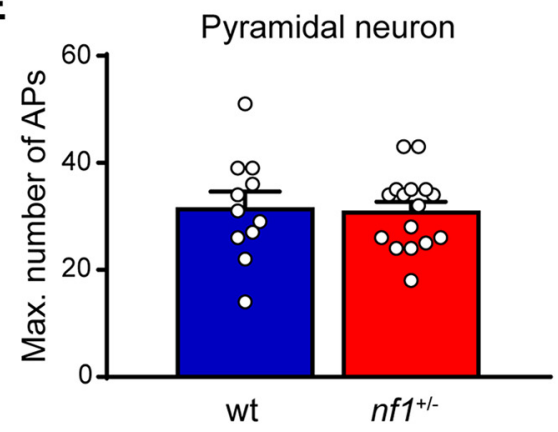

Figure 4. Increased excitability of inhibitory neurons. $\boldsymbol{A}$, Immunohistochemical example of a $\mathrm{PV}^{+}$inhibitory neuron, confirming the correct cell type was patched based on morphology. $\boldsymbol{B}$, C, Excitability of $L 2 / 3$ fast-spiking interneurons is increased in $n f 1^{+/-}$mice compared with WT mice during the critical period for OD plasticity as assessed by $(\boldsymbol{B})$ the number of APs induced by current injection (two-way ANOVA, genotype effect, $F_{(1,19)}=4.78, p=0.04$, area under curve comparison, $t$ test, $p=0.04$ ) and $(C)$ the maximum number of APs (Mann-Whitney, $p=0.02$; WT: $n=12$ cells from 5 mice, $n f 1^{+/-}: n=9$ cells from 5 mice). $\boldsymbol{D}, \boldsymbol{E}$, Excitability of $\mathrm{L} 2 / 3$ pyramidal neurons is not different between WT and $n f 1^{+/-}$mice during the critical period for $0 \mathrm{D}$ plasticity as assessed by $(\boldsymbol{D})$ the number of APs induced by current injection the number of APs induced by current injection (two-way ANOVA, genotype effect, $F_{(1,25)}=0.36, p=0.55$, area under curve comparison, $t$ test, $p=0.55$ ) and $(\boldsymbol{E})$ the maximum number of APs (Mann-Whitney, $p=0.80$; WT: $n=11$ cells from 5 mice, $n f 1^{+/-}: n=16$ cells from 6 mice). ${ }^{*} p<0.05$.

early. To differentiate between these possibilities, we again used optical imaging of intrinsic signal to determine the OD in $n f 1^{+/-}$ mice and their control littermates that were either monocularly deprived for $3 \mathrm{~d}$ at the beginning of the normal critical period (P21-P24) or reared normally. We found that $3 \mathrm{~d}$ of MD starting at P21 induced an OD shift in $n f 1^{+/-}$mice that was comparable with that in littermate controls (Fig. 7E). We conclude that OD plasticity in $n \mathrm{fl}^{+/-}$mice is only reduced at the later phase of the critical period, suggesting that the $n f 1^{+/-}$mutation does not interfere with OD plasticity per se, but causes premature closure of the critical period.

\section{Normal onset of the critical period of plasticity in V1 of} $n \mathbf{~ f ~}^{+/-}$mice

The early increase in inhibitory inputs soon after eye opening may also influence the onset of the critical period in $n f 1^{+/-}$mice. To test this, we determined the onset of the critical period of OD plasticity by subjecting $n \mathrm{fl}^{+/-}$and WT mice to $3 \mathrm{~d}$ of
$\mathrm{MD}$, starting at P15 or P17 and assessing whether this induced a shift in OD compared with nondeprived littermates. We found that $3 \mathrm{~d}$ of MD at P15 did not induce an OD shift in $n \mathrm{fl}^{+/-}$and WT mice, indicating that, on this genetic background, the critical period for OD plasticity had not yet started (Fig. 7F). However, after $3 \mathrm{~d}$ of MD starting at P17, both $n f 1^{++}$mice and littermate controls showed a full OD shift, indicating that, at that age, the critical period had started in mice of both genotypes. Thus, the opening of the critical period for OD plasticity occurs normally in $n f 1^{+/-}$mice, implying that the total duration of the critical period in these animals is reduced.

Early environmental enrichment rescues plasticity phenotype in $\mathrm{V} 1$ of $n f 1^{+/-}$mice by acting on inhibition levels

Previous work has shown that enriching the environment of mice by physical, social, and cognitive stimulation reduces 
A

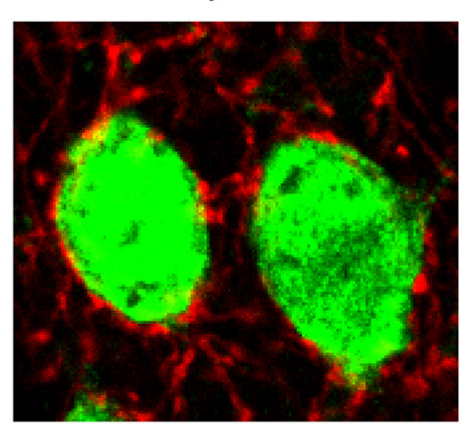

B

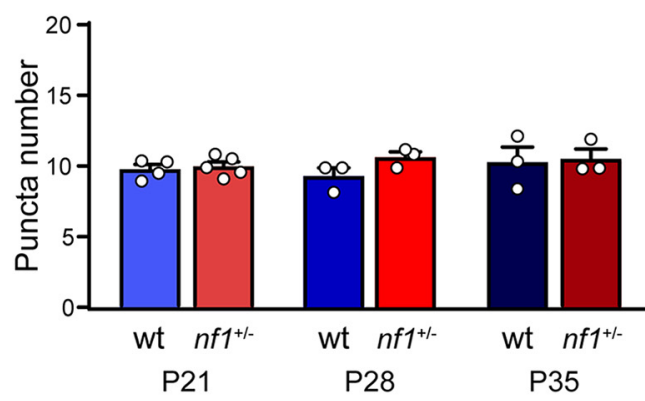

C

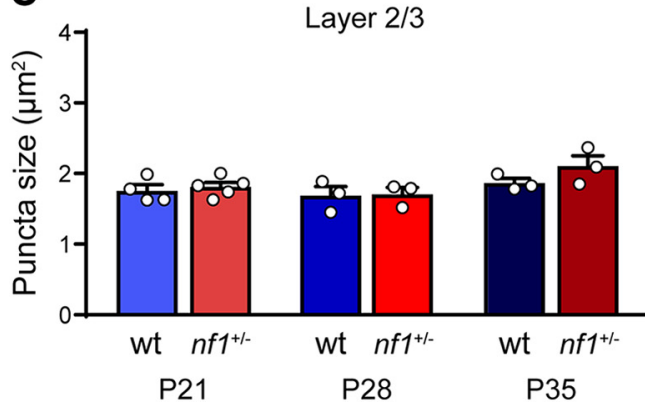

Layer 5

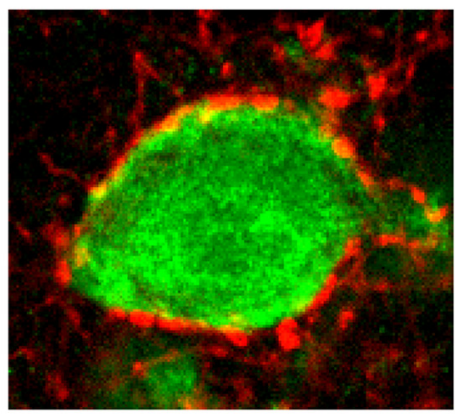

Layer 5

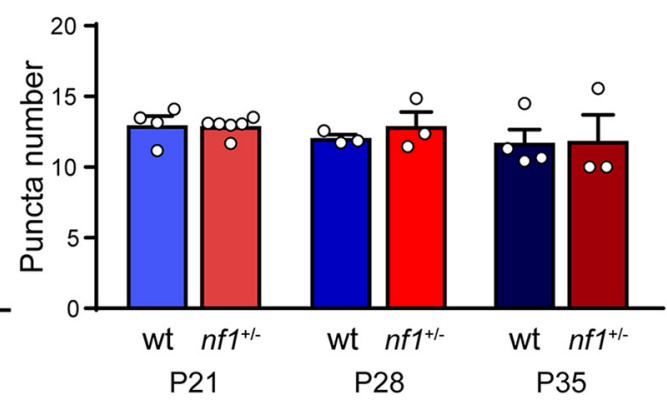

Layer 5

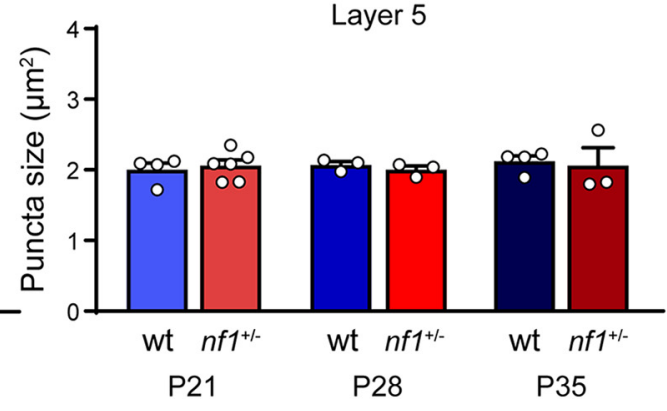

Figure 5. No change in size and density of boutons formed by $\mathrm{PV}^{+}$neurons. $A$, Immunohistochemical examples of the soma (green) of a $L 2 / 3$ and $L 5$ pyramidal neuron with puncta formed by synaptotagmin-2 positive (syt2) neurons (red). $\boldsymbol{B}$, The number of syt2 puncta is not different between WT and $n f 1^{+1-}$ mice in L2/3 ( $t$ test, P21: $p=0.68$, WT: $n=4$ mice, $n f 1^{+1-}: n=5$ mice; P28: $p=0.11$, WT: $n=3$ mice, $n f 1^{+/-}: n=3$ mice; P35: $p=0.85$, WT: $n=3$ mice, $n f 1^{+/-}: n=3$ mice) or in L5 (t test, P21: $p=0.90$, WT: $n=4$ mice, $n f 1^{+/-}: n=6$ mice; P28: $p=0.46$, WT: $n=3$ mice, $n f 1^{+/-}: n=3$ mice; P35: $p=0.95$, WT: $n=4$ mice, $n f 1^{+/-}: n=3$ mice). C, The size of syt2 puncta is also not different between WT and $n f 1^{+/-}$mice in L2/3 (t test, P21: $p=0.90 ; \mathrm{P} 28: p=0.91 ; \mathrm{P} 35: p=0.22$ ) or in L5 ( $t$ test, P21: $p=0.66 ; \mathrm{P} 28: p=0.42 ; \mathrm{P} 35: p=0.81$ ).

inhibitory innervation and enhances OD plasticity (Sale et al., 2007; Begenisic et al., 2011; Greifzu et al., 2014). Therefore, we wondered whether rearing $n f 1^{+/-}$mice in an enriched environment would also normalize the inhibition/excitation ratio and restore critical period plasticity. To this end, we housed pregnant mothers in Marlau cages, which contain a running wheel and are composed of a ground floor comprising two compartments: one with food and one with water, which can only be reached through an upper floor where a maze is placed that is regularly changed. Pups were reared in this environment until the time of the experimental measurement. We first assessed whether environmental enrichment affected inhibitory innervation. Previous work had shown that enrichment reduced inhibition in V1 in adulthood, but not during the critical period (Begenisic et al., 2011). As inhibition had already increased considerably in P28 $n f 1^{+l-}$ mice and the critical period was closed, we were curious to see whether environmental enrichment would normalize inhibition or whether it would have no influence at this age. We measured sIPSCs from pyramidal neurons in cortical layers $2 / 3$ of $\mathrm{V} 1$ in $n f 1^{+/-}$and WT mice after environmental enrichment.
We found that sIPSCs recorded from layer $2 / 3$ pyramidal neurons of $n f 1^{+/-}$or WT mice reared in an enriched environment did not show a difference in either amplitude or frequency (Fig. $8 A-D)$. The excitability of layer $2 / 3$ pyramidal neurons, as measured by the number of APs fired with current injection, was also not different between WT and $n f 1^{+/-}$mice that were reared in an enriched environment (Fig. $8 E, F$ ). This indicates that, after environmental enrichment, inhibition and excitation are the same in $n f 1^{+/-}$and WT mice.

Considering that environmental enrichment could make the difference in inhibition/excitation between $n f 1^{+/-}$and WT mice disappear, we wanted to know whether it would also normalize OD plasticity at the peak of the critical period. To test this, we again used optical imaging of intrinsic signal to determine the OD in $n f 1^{+/-}$mice and WT littermates that were monocularly deprived for $3 \mathrm{~d}$ (P28-P31), and in nondeprived mice. This revealed that $3 \mathrm{~d}$ of $\mathrm{MD}$ induced an $\mathrm{OD}$ shift both in enriched $n f 1^{+/-}$mice and their WT littermates (Fig. 8G). Interestingly, when we assessed the absolute responses of $\mathrm{V} 1$ responses to the deprived contralateral eye and the nondeprived 
A

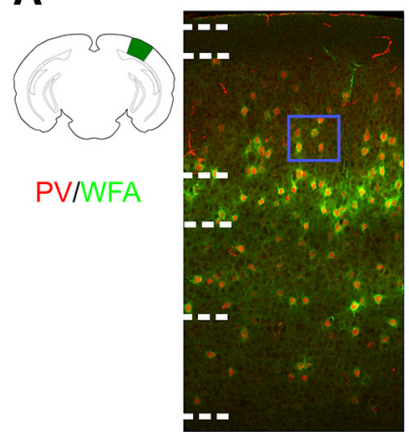

wt

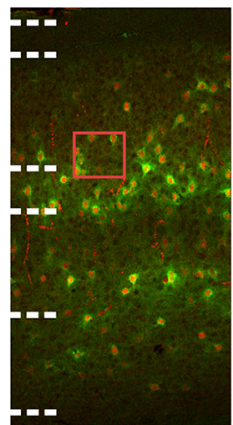

$n f 1^{+/-}$
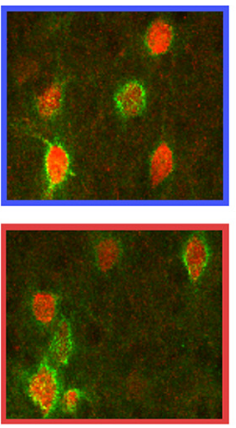

Close-up

B
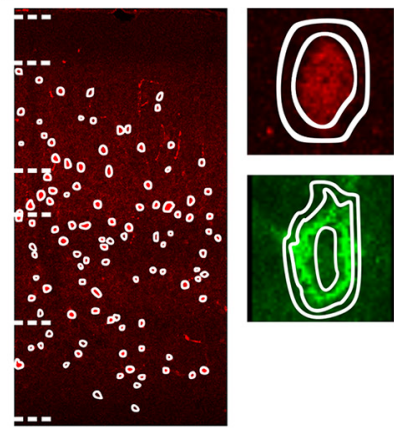

WFA intensity
C

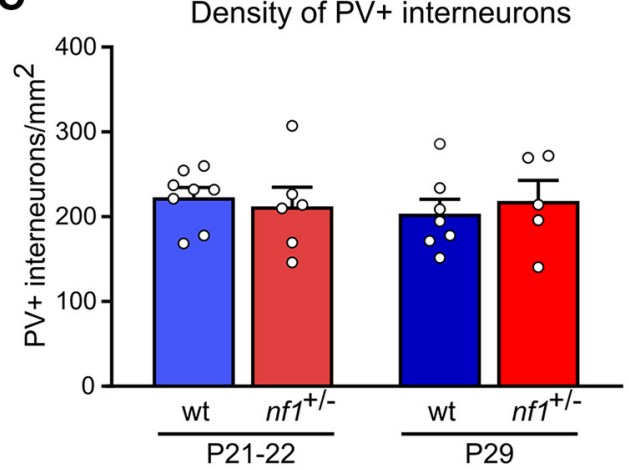

E

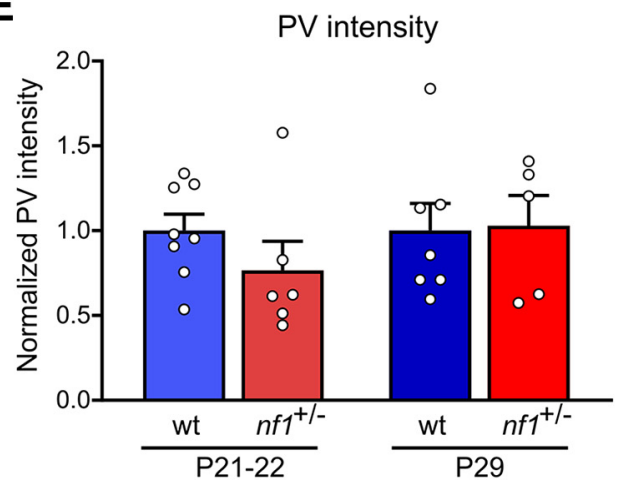

D

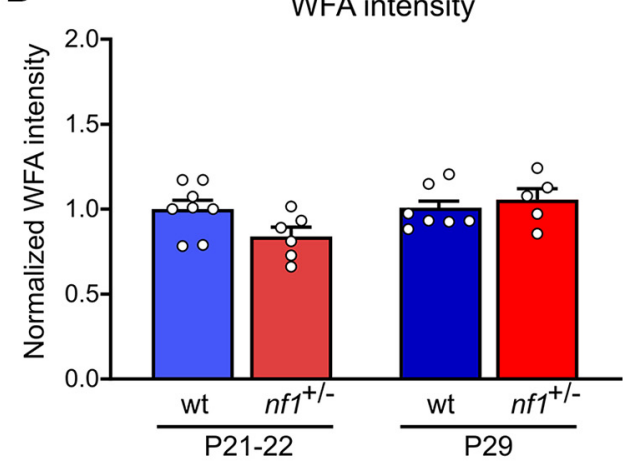

F

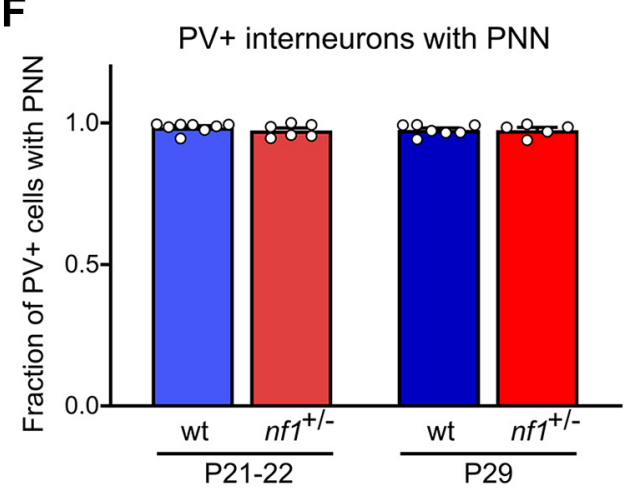

Figure 6. No changes in maturation markers of $\mathrm{PV}^{+}$neurons at the onset and peak of the critical period. $A$, Immunohistochemical examples of PNNs in green and PV ${ }^{+}$interneurons of WT and $n f 1^{+/-}$mice at the onset (P21-P22). The schematic representation of the location of V1 was adapted from the Allen Brain Atlas. B, Left, Example ROls used for the quantification of the $\mathrm{PV}^{+}$interneurons density. Top right, example ROI used for the measurement of PV intensity (inner circle) and the surrounding background (between inner and outer circle). Bottom right, Example ROl used for the measurement of WFA intensity (between inner and middle circle) and the surrounding background (between middle and outer circle). $C$, The number of PV ${ }^{+}$interneurons per $\mathrm{mm}^{2}$ did not differ between WT and $n f 1^{+/-}$mice at P21-P22 ( $t$ test, $p=0.66$; WT: $n=8$ mice, $n f 1^{+/-}: n=6$ ) or P29 ( $t$ test, $p=0.61 ;$ WT: $\left.n=7, n f 1^{+/-}: n=5\right)$ (for the distribution of $\mathrm{PV}^{+}$interneurons per cortical layer, see Extended Data Figure 6-1A). D. At P21-P22, WFA intensity around PV ${ }^{+}$interneurons in V1 appeared to be slightly lower in $n f 1^{+/-}$mice but did not differ significantly from WT mice ( $t$ test, $p=0.06$; WT: $n=8$ mice, $n f 1^{+/-}: n=6$ ). No difference was observed at P29 (Mann-Whitney, $p=0.50 ;$ WT: $n=7, n f 1^{+/-}: n=5$ ) (for WFA intensity per layer, see Extended Data Figure 6-1C). E, PV intensity showed a similar pattern with a nonsignificant trend toward lower expression in $n f 1^{+l-}$ mice at P21-P22 ( $t$ test, $p=0.23$; WT: $n=8$ mice, $\left.n f 1^{+/-}: n=6\right)$, which was absent at P29 ( $t$ test, $p=0.91 ;$ WT: $\left.n=7, n f 1^{+/-}: n=5\right)$. The PV and WFA intensities were normalized by dividing the signal by the average intensity across the age-matched WT mice. Extended Data Figure 6-1B shows the PV intensity per layer. $F$, The fraction of PV ${ }^{+}$interneurons enwrapped by a PNN in V1 was similar between $n f 1^{+l-}$ mice and WT littermates at P21-P22 (Mann-Whitney, $p=0.57$; WT: $n=8, n f 1^{+/-}: n=6$ ) and P29 (Mann-Whitney, $p>0.99 ;$ WT: $n=7, n f 1^{+/-}: n=5$ ) (for fraction of PV ${ }^{+}$interneurons with PNN per layer, see Extended Data Figure 6-1D).

ipsilateral eye, we found that the OD shift in WT mice was caused predominantly by a strengthening of the nondeprived eye responses. In $n \mathrm{fl}^{+/-}$mice, the strengthening of the nondeprived eye responses was also visible but not significant, and the OD shift involved a combination with reduced responsiveness to the deprived eye. This suggests that environmental enrichment improves the plasticity deficit in of $n f 1^{+/-}$mice, but also changes plasticity mechanisms during the critical period.

\section{Discussion}

In this study, we show that, in $n f 1^{+/-}$mice, cortical inhibition increases rapidly after eye opening and remains higher than in WT mice throughout the critical period of OD plasticity. While we did not find changes in spontaneous activity patterns during early cortical development in $n f 1^{+/-}$mice, the critical period of OD plasticity was shortened due to its precocious closure. Therefore, we propose that cognitive and behavioral symptoms 


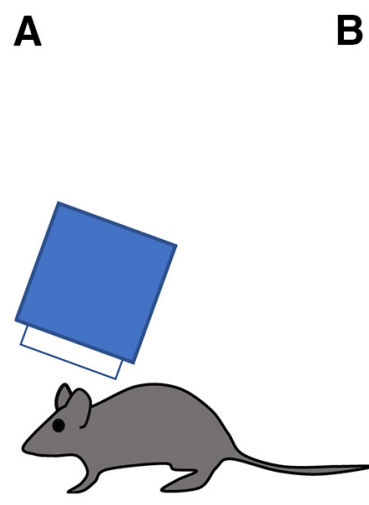

C
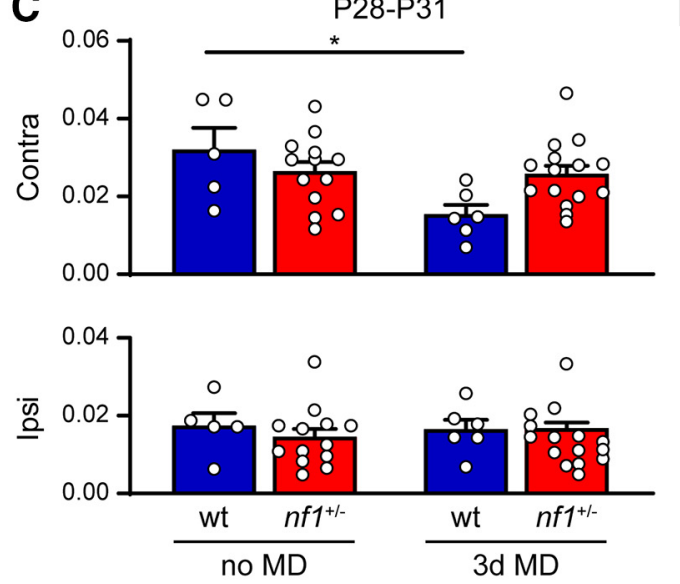

Retinotopy
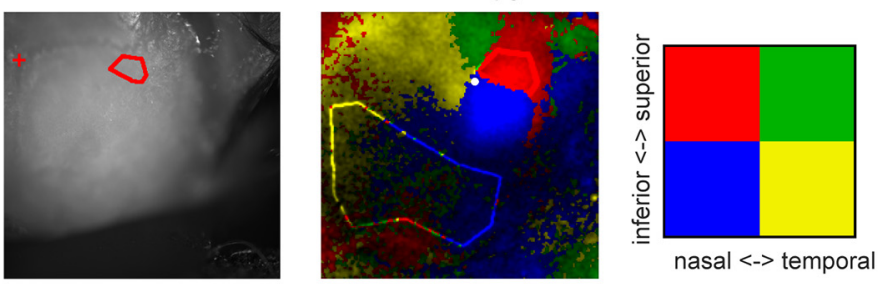

Ocular dominance measurement

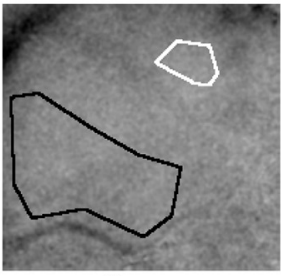

None

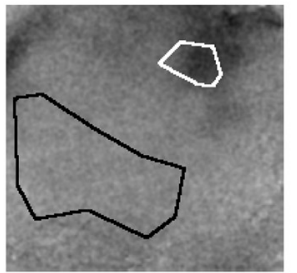

Ipsi
D

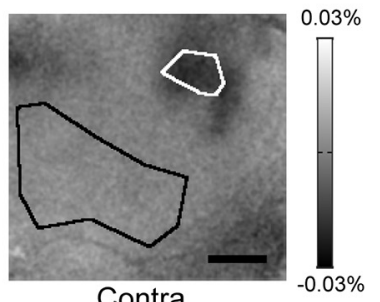

P28-P31
E

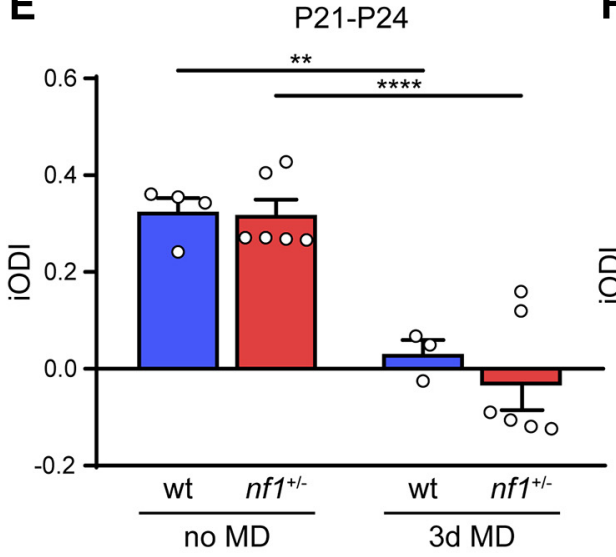

$\mathbf{F}$

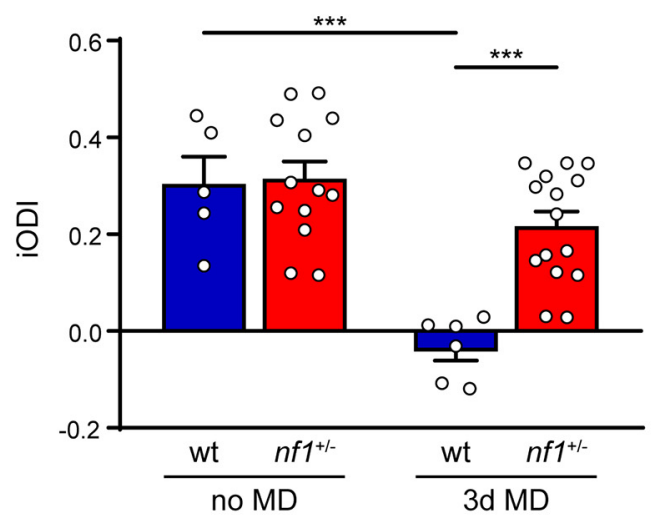

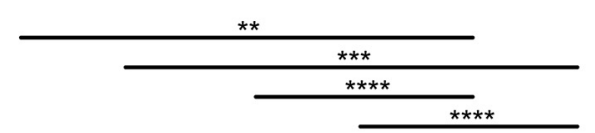

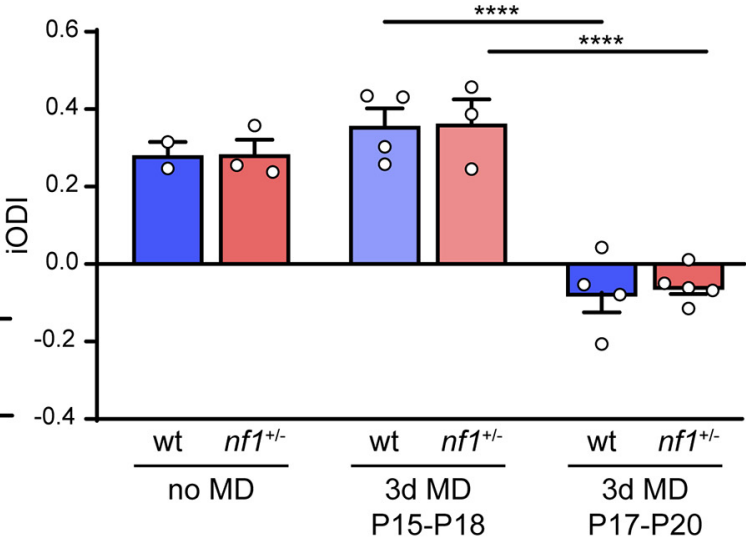

Figure 7. Precocious closure but normal onset of the critical period of plasticity in $\mathrm{V} 1$ of $n f 1^{+/-}$mice. $A$, Schematic illustration of experimental approach. To determine $0 \mathrm{D}$ plasticity in mice, optical imaging of intrinsic signal is used in mice during the peak of the critical period, or around its onset. $\boldsymbol{B}$, Top, Example of a cranial image and retinotopy created by visual stimulation with $2 \times 2$ patches of drifting gratings. The upper nasal part is used as an ROI, and an area outside V1 as a reference for the OD measurements. Bottom, Transcranial images of change in light reflection in V1, in response to individual eye stimulation in a nondeprived mouse. C, Absolute change in responses to input from the contralateral or ipsilateral eye. Three day MD at P28-P31 causes a loss of deprived, contralateral eye responses in WT, but not $n f 1^{+/-}$mice (two-way ANOVA, $F_{(1,35)}=6.03, p=0.02$, post hoc Tukey's, no MD WT vs $3 \mathrm{~d}$ MD WT: $p=0.02$; no MD $n f 1^{+/-}$vs $3 \mathrm{~d} \mathrm{MD} \mathrm{nf1^{+/- }}: p=0.998 ; 3 \mathrm{~d}$ MD WT vs $3 \mathrm{~d} \mathrm{MD} \mathrm{nf1^{+/- }}: p=0.10$ ), whereas nondeprived, ipsilateral eye responses remain the same (two-way ANOVA, $F_{(1,35)}=0.41, p=0.53 ;$ WT no MD: $n=5$ mice, $n f 1^{+/-}$no MD: $n=13$ mice, WT $3 \mathrm{~d}$ MD: $n=6$ mice, $n f 1^{+/-} 3 \mathrm{~d} \mathrm{MD:} n=15$ mice). D, iODI is calculated from the data in $\boldsymbol{C}$ and is defined by the following: (contralateral response - ipsilateral response)/(contralateral response + ipsilateral response). iODI shows that $3 \mathrm{~d}$ MD at P28-P31 induces a larger OD shift in WT mice than in $n f 1^{+/-}$mice (two-way ANOVA, $F_{(1,35)}=8.58, p=0.006$, post hoc Tukey's, WT no MD vs WT $3 \mathrm{~d}$ MD, $p=0.0001, n f 1^{+/-}$no MD vs $n f 1^{+/-} 3 \mathrm{~d}$ MD, $p=0.4720$, WT $3 \mathrm{~d}$ MD vs $n f 1^{+/-} 3 \mathrm{~d}$ MD, $\left.p=0.0004\right)$. $E$, iODI shows that 3d MD between P21 and P24 induces a full OD shift in both WT and $n f^{+/-}$mice (two-way ANOVA, 3d MD effect, $F_{(1,15)}=52.12, p<0.0001$, post hoc Tukey's, WT no MD vs WT $3 \mathrm{~d} \mathrm{MD}, p=0.004, n f 1^{+/-}$vs $n f 1^{+/-} 3 \mathrm{~d} \mathrm{MD}, p<0.0001$, WT $3 \mathrm{~d} \mathrm{MD} \mathrm{vs} n f 1^{+/-} 3 \mathrm{~d}$ MD, $p=0.82$, WT no MD: $n=4$ mice, $n f 1^{+/-}$no MD: $n=6$, WT $3 \mathrm{~d}$ MD: $\left.n=3, n f 1^{+/-} 3 \mathrm{~d} \mathrm{MD}: n=6\right) . \boldsymbol{F}$, iODI shows that $3 \mathrm{~d}$ MD between P17 and P20 induces a full OD shift in both WT and $n f 1^{+/-}$mice, whereas no OD shift occurs $2 \mathrm{~d}$ earlier between P15 and P18 (two-way ANOVA, $3 \mathrm{~d}$ MD effect, $F_{(2,15)}=60.86, p<0.0001$, post hoc Tukey's, WT: no MD vs 3d MD P15-P18, $p=0.88, n f 1^{+/-}$: no MD vs $3 \mathrm{~d}$ MD P15-P18, $p=0.83$, WT: no MD vs 3d MD P17-P20, $p=0.002, n f 1^{+/-}$: 
in NF1 are partially caused by dysregulation of critical periods of development caused by increased levels of cortical inhibition. This implies that treatments of the cognitive aspects of the disorder need to begin at a very young age, and that later attempts to correct increased levels of inhibition may only be partially effective.

Our recordings of inhibitory currents in layer $2 / 3$ pyramidal neurons of $\mathrm{V} 1$ revealed that spontaneous inhibitory currents occurred more frequently in $n f 1^{+/-}$mice. This was first observed after eye opening and continued during the critical period. The frequency and amplitudes of mIPSCs were not altered, suggesting that changes in vesicle release probability or synapse numbers did not occur. This is in line with previous work in $n f 1^{+/-}$ mice showing that GABA release was only increased under conditions that mimicked high-frequency stimulation (Cui et al., 2008). We therefore tested another possible explanation for the increase in inhibition: increased excitability of cortical interneurons. It was recently shown that $\mathrm{HCN} 1$ interacts with the $\mathrm{N}$ terminal part of the neurofibromin protein. In mice carrying a mutated $n f 1$ gene, HCN1 levels in hippocampus were reduced and Ih currents were strongly diminished causing increased neuronal excitability that was not mediated by enhanced Ras-MAPK signaling (Omrani et al., 2015). This mostly affected GABAergic neurons because they express the highest level of HCN1. In line with these findings, we found that, in V1 of $n f 1^{+/-}$mice, fastspiking interneurons, but not layer $2 / 3$ pyramidal neurons, showed an increase in excitability during the critical period. This suggests that, also during cortical development, reduced $n f 1$ expression results in increased inhibition due to HCN1 dysfunction in inhibitory neurons.

Despite the increased cortical inhibition, we did not notice any differences in spontaneous activity patterns in developing $\mathrm{V} 1$ of $n f 1^{+/-}$mice as assessed by in vivo two-photon calcium imaging. This contrasts with the situation in a mouse model of Fragile-X in which a considerable reduction in the ratio of $\mathrm{L}-$ to H- events was observed (Cheyne et al., 2019). It thus appears that developmental deficits in NF1 start later than in Fragile-X. However, it is also possible that more subtle changes in spontaneous activity occur in $n f 1^{+/-}$mice that we did not notice using our approach. It is thus important to investigate in the future whether refinement of connections at the subcellular level are affected by changes in inhibitory innervation in $n f 1^{+/-}$mice.

The critical period of OD plasticity was shortened in $n \mathrm{fl}^{+/-}$ mice. While it closed earlier in $n f 1^{+/-}$mice, it started at the same time as in WT littermates. This observation also supports the idea that NF1 mostly affects later stages of visual cortical development, when the critical period has already opened. This differs from the situation in other mouse models in which increased inhibition around the time of eye opening caused a precocious onset of the critical period, such as BDNF transgenic mice (Hanover et al., 1999; Huang et al., 1999) and mice treated with benzodiazepine, a positive allosteric GABA(A)-receptor modulator (Fagiolini and Hensch, 2000). One possible explanation for the different situation in $n f 1^{+/-}$mice could be that the development of inhibitory innervation in BDNF transgenic mice (Huang

$\leftarrow$

no MD vs 3d MD P17-P20, $p=0.0004$, WT: 3d MD P15-P18 vs 3d MD P17-P20, $p<0.0001$,

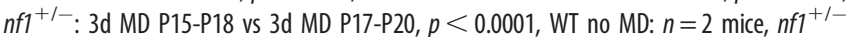
no MD: $n=3$, WT P15-P18: $n=4, n f 1^{+/-}$P15-P18: $n=3$, WT P17-P20: $n=4, n f 1^{+1-}$ ). ${ }^{*} p<0.05,{ }^{* *} p<0.01,{ }^{* * *} p<0.001,{ }^{* * * *} p<0.0001$. et al., 1999) and benzodiazepine-treated mice (Iwai et al., 2003) was also advanced, while this was not the case in $n f 1^{+/-}$mice. A recent study in mice in which $n f 1$ was inactivated in precursors of cortical interneurons (Angara et al., 2020) showed evidence that $n f 1$ deletion could even delay $\mathrm{PV}^{+}$interneuron development. Fewer PNNs were found in somatosensory cortex of these mice. $\mathrm{PV}^{+}$expression was also affected by $n f 1$ deletion, but only if both alleles were inactivated. In $\mathrm{V} 1$ of $n f 1^{+/-}$mice, we also noticed some reduction of WFA and PV expression at the onset of the critical period, but the differences were not significant. It is thus possible that advanced development of inhibitory innervation is necessary for an early critical period onset, and that the mere increase in excitability of fast-spiking interneurons as observed in $n f 1^{+/-}$mice is not sufficient.

The critical period did close prematurely, however, effectively shortening its duration. Possibly, near the end of the critical period, the increased excitability of interneurons in $n f 1^{+/-}$mice interferes with the temporary reduction of $\mathrm{PV}^{+}$interneuron activity required for OD plasticity (Kuhlman et al., 2013). Although we only assessed inhibitory inputs and OD plasticity in the upper layers of V1, we expect that deeper layers are similarly affected in $n f 1^{+/-}$mice. Interneurons in all cortical layers express high levels of HCN1, and the OD shift measured in the superficial layers is a reflection of rearrangements of both intralaminar horizontal connections (Trachtenberg et al., 2000; Trachtenberg and Stryker, 2001) and thalamocortical and layer 4 projections to layer 2/3 (Liu et al., 2008; Khibnik et al., 2010).

The shortening of critical periods by itself may cause learning deficits, due to the limited time available for experience-dependent network refinement. But more intricate problems may also occur, as critical periods take place in a temporal order, with lower cortical regions undergoing plasticity before higher regions. Their temporal dysregulation may thus affect developmental interactions between cortical regions, potentially resulting in complex cognitive, behavioral, or motor deficits, such as the visuospatial deficits often observed in NF1, which involve various brain regions, including V1 (Clements-Stephens et al., 2008). Dysregulation of critical periods has also been found in some other mouse models of monogenetic neurodevelopmental disorders, including Rett syndrome and Fragile X. In Rett syndrome, it was found that synaptic mechanisms were responsible for accelerated development of cortical inhibition (Durand et al., 2012; Krishnan et al., 2015), although reduced inhibition was observed in another study (Banerjee et al., 2016), resulting in both a premature onset and closure of the critical period of OD plasticity (Krishnan et al., 2015). This illustrates that neurodevelopmental problems may also arise when the critical period is not shortened but only shifted in time. Thus, critical period disruption may be a common theme in neurodevelopmental disorders, and the precise timing of critical periods in different brain regions may be crucial for proper brain development.

Because our findings and previous studies all indicate that increased inhibition contributes to the cognitive deficits in NF1 (Costa et al., 2002; Cui et al., 2008; Shilyansky et al., 2010; Omrani et al., 2015), reducing GABAergic transmission seems like a sensible therapeutic approach. It may, however, be challenging to correct critical period deficits using pharmacology, as different brain regions may require reduced inhibition at different ages. We therefore investigated whether environmental enrichment would provide a promising alternative (Castrén et al., 2012). Previous work has shown that environmental enrichment decreases inhibition and enhances OD plasticity (Sale et al., 
A

B
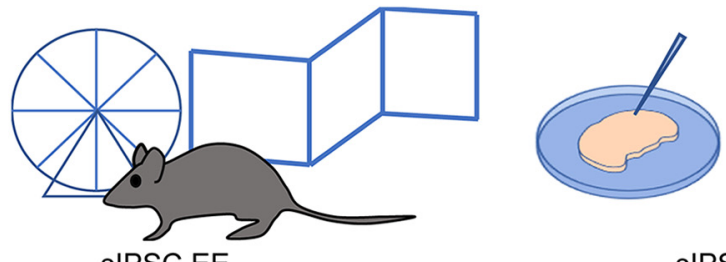

SIPSC EE

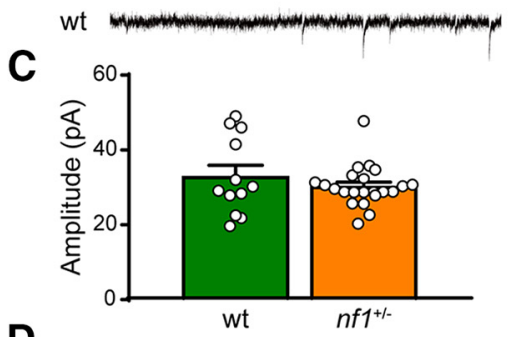

D

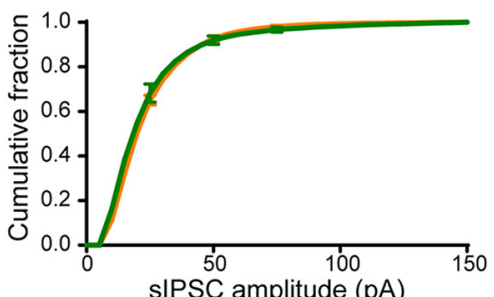

E

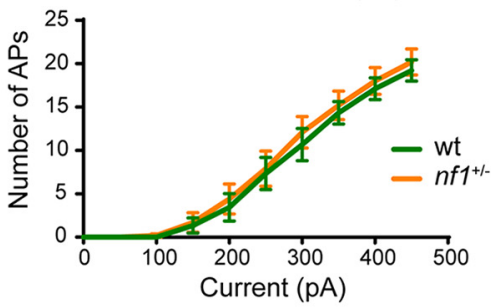

G

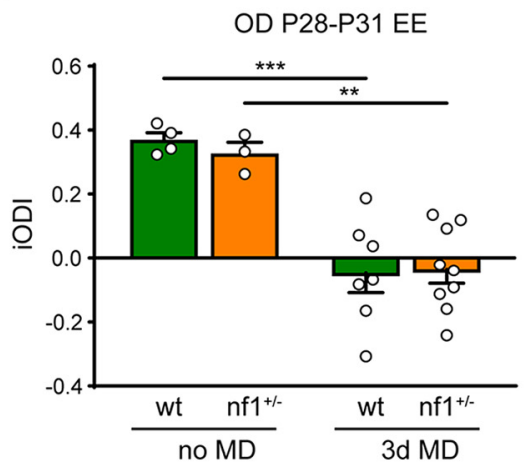

SIPSC EE
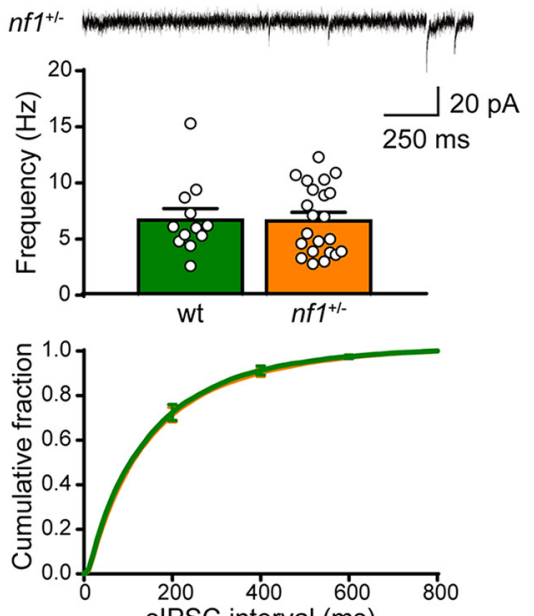

$\mathbf{F}$

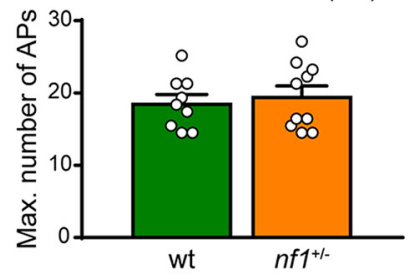

H

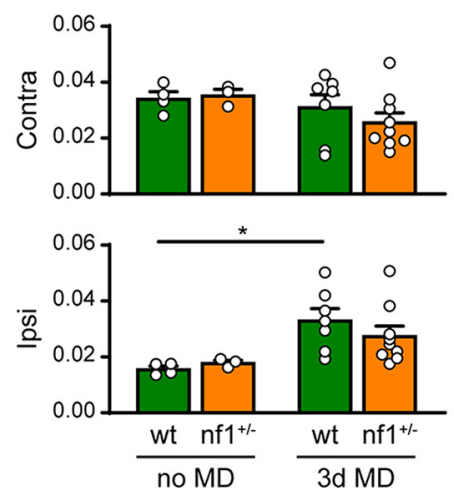

Figure 8. Early environmental enrichment rescues plasticity phenotype in $\mathrm{V} 1$ of $n \mathrm{fi}^{+/-}$mice by acting on inhibition levels. $\boldsymbol{A}$, Schematic illustration of experimental approach. Electrophysiological recordings and optical imaging experiments were performed in mice around P28, which are raised in an enriched environment (EE). $\boldsymbol{B}$, Representative traces of sIPSCS in L2/3 of V1 in EE-raised WT and $n f 1^{+/-}$mice. $C$, EE-raised $n f 1^{+/-}$and WT mice have the same average sIPSC amplitude (Mann-Whitney, $p=0.91$, WT: $n=12$ cells from 3 mice, $n f 1^{+/} n=22$ cells from 7 mice) and frequency (Mann-Whitney, $p=0.95$ ). $\boldsymbol{D}$, Cumulative distributions of sIPSC amplitudes and interevent intervals of EE-raised WT and $n f 1^{+/-}$mice. $\boldsymbol{E}, \boldsymbol{F}$, Excitability of L2/3 pyramidal neurons is not different between EE-raised WT and $n f 1^{+/-}$mice during the critical period as assessed by $(\boldsymbol{E})$ the number of APs induced by current injection (two-way ANOVA, interaction genotype/excitability, $p=0.79$ ) and $(\boldsymbol{F})$ the maximum number of APs ( $t$ test, $p=0.63$; WT: $n=9$ cells from 3 mice, $n f 1^{+/-}: n=10$ cells from 5 mice). G, Imaged iODI shows that $3 \mathrm{~d}$ MD at P28-P31 induces an OD shift in both WT and $n f 1^{+/-}$mice, when raised in an enriched environment (two-way ANOVA, $3 \mathrm{~d}$ MD effect, $F_{(1,19)}=$ 44.62, $p<0.0001$, post hoc Tukey's, WT no MD vs WT $3 \mathrm{~d}$ MD, $p=0.0003 ; n f 1^{+/-}$no MD vs $n f 1^{+/-} 3 \mathrm{~d}$ MD, $p=0.002$; WT $3 \mathrm{~d}$ MD vs $n f 1^{+/-}$3d MD: $p=0.998$; WT no MD: $n=4$ mice, $n f 1^{+/-}$no MD: $n=3$ mice, WT $3 \mathrm{~d}$ MD: $n=7$ mice, $n f 1^{+/-} 3 \mathrm{~d}$ MD: $n=9$ mice). $\boldsymbol{H}$, Absolute change in contralateral and ipsilateral responses. 3d MD at P28-P31 causes an increase of nondeprived eye responses in WT. This trend is also visible, but not significant, in $n f 1^{+/-}$mice (two-way ANOVA, $3 \mathrm{~d}$ MD effect, $F_{(1,19)}=$ $10.16, p=0.005$, post hoc Tukey's, no MD WT vs $3 \mathrm{~d}$ MD WT: $p=0.03$; no MD nf1 ${ }^{+/-}$vs $3 \mathrm{~d} \mathrm{MD} \mathrm{nf1^{+/- }}: p=0.43$; WT $3 \mathrm{~d}$ MD vs $n f 1^{+/-} 3 \mathrm{~d}$ MD: $p=0.63$ ), whereas deprived eye responses remain the same (two-way ANOVA, $3 \mathrm{~d}$ MD effect, $F_{(1,19)}=2.13$, $p=0.16) .{ }^{*} p<0.05,{ }^{* *} p<0.01,{ }^{* *} p<0.001$.

2007; Baroncelli et al., 2010; Begenisic et al., 2011; Greifzu et al., 2014). We found that, in $n f 1^{+/-}$mice, differences in OD plasticity and inhibitory innervation disappeared after environmental enrichment, showing it can indeed improve the plasticity deficits. After environmental enrichment, the OD shift could be induced by brief MD, typical for critical period plasticity, in WT and $n f 1^{+/-}$mice. Surprisingly, in WT mice, the shift was caused predominantly by increased responses to the nondeprived eye, typical for adult OD plasticity. This trend, though not significant, was also visible in $n f 1^{+/-}$ mice. OD plasticity with characteristics of both adult and critical period plasticity was also observed in adult mice reared in an enriched environment (Kalogeraki et al., 2017). As previous studies noted that environmental enrichment also accelerates cortical development (Bartoletti et al., 2004; Cancedda et al., 2004; Sale et al., 2004), it is possible that in our hands it enhanced plasticity and accelerated V1 development at the same time. It is currently unknown through what mechanisms environmental enrichment affects inhibition. Interestingly, a recent study has shown that with age, Ih currents reduce in $\mathrm{PV}^{+}$interneurons in the developing cortex (Yang et al., 2018). As environmental manipulations are known to affect HCN1 channel function (Schridde et al., 2006), it is possible that enrichment increases Ih currents in $\mathrm{PV}^{+}$ interneurons, directly affecting the deficit observed in $n f 1^{+/-}$mice.

Together, our results support the idea that increased inhibition causes critical period dysregulation in NF1. This has important implications for pharmacological approaches for the treatment of cognitive symptoms in $\mathrm{NF} 1$, and suggest that such treatment may have to start at a very young age. Our observation that increased inhibition was caused by hyperexcitability of cortical interneurons emphasizes the importance of $\mathrm{HCN} 1$ channels as a therapeutic target. The finding that rearing mice in an enriched environment normalizes inhibition and enhances plasticity in $n f 1^{+/-}$mice suggests that training approaches may also be effective and could directly act on the increased inhibition observed in NF1 (Barquero et al., 2015; Arnold et al., 2016). 


\section{References}

Ackman JB, Burbridge TJ, Crair MC (2012) Retinal waves coordinate patterned activity throughout the developing visual system. Nature 490:219225.

Angara K, Pai EL, Bilinovich SM, Stafford AM, Nguyen JT, Li KX, Paul A, Rubenstein JL, Vogt D (2020) Nf1 deletion results in depletion of the Lhx6 transcription factor and a specific loss of parvalbumin ${ }^{+}$cortical interneurons. Proc Natl Acad Sci USA 117:6189-6195.

Arganda-Carreras I, Kaynig V, Rueden C, Eliceiri KW, Schindelin J, Cardona A, Sebastian Seung H (2017) Trainable Weka Segmentation: a machine learning tool for microscopy pixel classification. Bioinformatics 33:24242426.

Arnold SS, Barton B, McArthur G, North KN, Payne JM (2016) Phonics training improves reading in children with neurofibromatosis type 1: a prospective intervention trial. J Pediatr 177:219-226.e2.

Attardo A, Fitzgerald JE, Schnitzer MJ (2015) Impermanence of dendritic spines in live adult CA1 hippocampus. Nature 523:592-596.

Banerjee A, Rikhye RV, Breton-Provencher V, Tang X, Li C, Li K, Runyan CA, Fu Z, Jaenisch R, Sur M (2016) Jointly reduced inhibition and excitation underlies circuit-wide changes in cortical processing in Rett syndrome. Proc Natl Acad Sci USA 13:E7287-E7296.

Baroncelli L, Sale A, Viegi A, Maya Vetencourt JF, De Pasquale R, Baldini S, Maffei L (2010) Experience-dependent reactivation of ocular dominance plasticity in the adult visual cortex. Exp Neurol 226:100-109.

Barquero LA, Sefcik AM, Cutting LE, Rimrodt SL (2015) Teaching reading to children with neurofibromatosis type 1: a clinical trial with random assignment to different approaches. Dev Med Child Neurol 57:11501158.

Bartoletti A, Medini P, Berardi N, Maffei L (2004) Environmental enrichment prevents effects of dark-rearing in the rat visual cortex. Nat Neurosci 7:215-216.

Begenisic T, Spolidoro M, Braschi C, Baroncelli L, Milanese M, Pietra G, Fabbri ME, Bonanno G, Cioni G, Maffei L, Sale A (2011) Environmental enrichment decreases GABAergic inhibition and improves cognitive abilities, synaptic plasticity, and visual functions in a mouse model of Down syndrome. Front Cell Neurosci 5:29.

Benarroch EE (2013) HCN channels: function and clinical implications. Neurology 80:304-310.

Bonifazi P, Goldin M, Picardo MA, Jorquera I, Cattani A, Bianconi G, Represa A, Ben-Ari Y, Cossart R (2009) GABAergic hub neurons orchestrate synchrony in developing hippocampal networks. Science 326:14191424.

Cancedda L, Putignano E, Sale A, Viegi A, Berardi N, Maffei L (2004) Acceleration of visual system development by environmental enrichment. J Neurosci 24:4840-4848.

Castrén E, Elgersma Y, Maffei L, Hagerman R (2012) Treatment of neurodevelopmental disorders in adulthood. J Neurosci 32:14074-14079.

Champion JA, Rose KJ, Payne JM, Burns J, North KN (2014) Relationship between cognitive dysfunction, gait, and motor impairment in children and adolescents with neurofibromatosis type 1. Dev Med Child Neurol 56:468-474.

Chattopadhyaya B, Di Cristo G, Higashiyama H, Knott GW, Kuhlman SJ, Welker E, Huang ZJ (2004) Experience and activity-dependent maturation of perisomatic GABAergic innervation in primary visual cortex during a postnatal critical period. J Neurosci 24:9598-9611.

Cheyne JE, Zabouri N, Baddeley D, Lohmann C (2019) Spontaneous activity patterns are altered in the developing visual cortex of the Fmr1 knockout mouse. Front Neural Circuits 13:57.

Clements-Stephens AM, Rimrodt SL, Gaur P, Cutting LE (2008) Visuospatial processing in children with neurofibromatosis type 1 . Neuropsychologia 46:690-697.

Cnossen MH, Moons KG, Garssen MP, Pasmans NM, de Goede-Bolder A, Niermeijer MF, Grobbee DE (1998) Minor disease features in neurofibromatosis type 1 (NF1) and their possible value in diagnosis of NF1 in children $<$ or $=6$ years and clinically suspected of having NF1: Neurofibromatosis Team of Sophia Children's Hospital. J Med Genet 35:624-627.

Costa RM, Federov NB, Kogan JH, Murphy GG, Stern J, Ohno M, Kucherlapati R, Jacks T, Silva AJ (2002) Mechanism for the learning deficits in a mouse model of neurofibromatosis type 1. Nature 415:526-530.
Cui Y, Costa RM, Murphy GG, Elgersma Y, Zhu Y, Gutmann DH, Parada LF, Mody I, Silva AJ, Luis F (2008) Neurofibromin regulation of ERK signaling modulates GABA release and learning. Cell 135:549-560.

De Paola V, Holtmaat A, Knott G, Song S, Wilbrecht L, Caroni P, Svoboda K (2006) Cell type-specific structural plasticity of axonal branches and boutons in the adult neocortex. Neuron 49:861-875.

del Rio J, de Lecea L, Ferrer I, Soriano E (1994) The development of parvalbumin immunoactivity in the neocortex of the mouse. Brain Res Dev Brain Res 81:247-259.

Durand S, Patrizi A, Quast KB, Hachigian L, Pavlyuk R, Saxena A, Carninci P, Hensch TK, Fagiolini M (2012) NMDA receptor regulation prevents regression of visual cortical function in the absence of Mecp2. Neuron 76:1078-1090

Fagiolini M, Hensch TK (2000) Inhibitory threshold for critical-period activation in primary visual cortex. Nature 404:183-186.

Fares RP, Kouchi H, Bezin L (2012) Standardized environmental enrichment for rodents in Marlau cage. Protocol Exchange. Available at http://dx.doi. org/10.1038/protex.2012.036.

Ferner RE, Huson SM, Thomas N, Moss C, Willshaw H, Evans DG, Upadhyaya M, Towers R, Gleeson M, Steiger C, Kirby A (2007) Guidelines for the diagnosis and management of individuals with neurofibromatosis. J Med Genet 44:81-88.

Gonçalves J, Violante IR, Sereno J, Leitão RA, Cai Y, Abrunhosa A, Silva AP, Silva AJ, Castelo-Branco M (2017) Testing the excitation/inhibition imbalance hypothesis in a mouse model of the autism spectrum disorder: in vivo neurospectroscopy and molecular evidence for regional phenotypes. Mol Autism 8:47.

Greifzu F, Pielecka-Fortuna J, Kalogeraki E, Krempler K, Favaro PD, Schlüter OM, Löwel S (2014) Environmental enrichment extends ocular dominance plasticity into adulthood and protects from stroke-induced impairments of plasticity. Proc Natl Acad Sci USA 111:1150-1155.

Hanover JL, Huang ZJ, Tonegawa S, Stryker MP (1999) Brain-derived neurotrophic factor overexpression induces precocious critical period in mouse visual cortex. J Neurosci 19:RC40.

Heimel JA, Hartman RJ, Hermans JM, Levelt CN (2007) Screening mouse vision with intrinsic signal optical imaging. Eur J Neurosci 25:795-804.

Hensch TK (2005) Critical period plasticity in local cortical circuits. Nat Rev Neurosci 6:877-888.

Hensch TK, Fagiolini M, Mataga N, Stryker MP, Baekkeskov S, Kash SF (1998) Local GABA circuit control of experience-dependent plasticity in developing visual cortex. Science 282:1504-1508.

Huang ZJ, Kirkwood A, Pizzorusso T, Porciatti V, Morales B, Bear MF, Maffei L, Tonegawa S (1999) BDNF regulates the maturation of inhibition and the critical period of plasticity in mouse visual cortex. Cell 98:739-755

Hyman SL, Shores A, North KN (2005) The nature and frequency of cognitive deficits in children with neurofibromatosis type 1. Neurology 65:1037-1044

Iwai Y, Fagiolini M, Obata K, Hensch TK (2003) Rapid critical period induction by tonic inhibition in visual cortex. J Neurosci 23:6695-6702.

Kalogeraki E, Pielecka-Fortuna J, Löwel S (2017) Environmental enrichment accelerates ocular dominance plasticity in mouse visual cortex whereas transfer to standard cages resulted in a rapid loss of increased plasticity. PLoS One 12:e0186999.

Khibnik LA, Cho KK, Bear MF (2010) Relative contribution of feedforward excitatory connections to expression of ocular dominance plasticity in layer 4 of visual cortex. Neuron 66:493-500.

Krab LC, Aarsen FK, de Goede-Bolder A, Catsman-Berrevoets CE, Arts WF, Moll HA, Elgersma Y (2008a) Impact of neurofibromatosis type 1 on school performance. J Child Neurol 23:1002-1010.

Krab LC, de Goede-Bolder A, Aarsen FK, Pluijm SM, Bouman MJ, van der Geest JN, Lequin M, Catsman CE, Arts WF, Kushner SA, Silva AJ, de Zeeuw CI, Moll HA, Elgersma Y (2008b) Effect of simvastatin on cognitive functioning in children with neurofibromatosis type 1. JAMA 300:287-294.

Krab LC, Goorden SM, Elgersma Y (2008c) Oncogenes on my mind: ERK and MTOR signaling in cognitive diseases. Trends Genet 24:498-510.

Krab LC, Oostenbrink R, de Goede-Bolder A, Aarsen FK, Elgersma Y, Moll HA (2009) Health-related quality of life in children with neurofibromatosis type 1: contribution of demographic factors, disease-related factors, and behavior. J Pediatr 154:420-425.e1. 
Krishnan K, Wang BS, Lu J, Wang L, Maffei A, Cang J, Huang ZJ (2015) $\mathrm{MeCP} 2$ regulates the timing of critical period plasticity that shapes functional connectivity in primary visual cortex. Proc Natl Acad Sci USA 112: E4782-E4791.

Kuhlman SJ, Olivas ND, Tring E, Ikrar T, Xu X, Trachtenberg JT (2013) A disinhibitory microcircuit initiates critical-period plasticity in the visual cortex. Nature 501:543-546.

Lee H, Brott BK, Kirkby LA, Adelson JD, Cheng S, Feller MB, Datwani A, Shatz CJ (2014) Synapse elimination and learning rules co-regulated by MHC class I H2-Db. Nature 509:195-200.

Leighton AH, Lohmann C (2016) The wiring of developing sensory circuits: from patterned spontaneous activity to synaptic plasticity mechanisms. Front Neural Circuits 10:1-13.

Liu CH, Heynen AJ, Shuler MG, Bear MF (2008) Cannabinoid receptor blockade reveals parallel plasticity mechanisms in different layers of mouse visual cortex. Neuron 58:340-345.

Mooney R, Penn AA, Gallego R, Shatz CJ (1996) Thalamic relay of spontaneous retinal activity prior to vision. Neuron 17:863-874.

Omrani A, van der Vaart T, Mientjes E, van Woerden GM, Hojjati MR, Li KW, Gutmann DH, Levelt CN, Smit AB, Silva AJ, Kushner SA, Elgersma Y (2015) HCN channels are a novel therapeutic target for cognitive dysfunction in Neurofibromatosis type 1. Mol Psychiatry 20:1311-1321.

Payne JM, Barton B, Ullrich NJ, Cantor A, Hearps SJ, Cutter G, Rosser T, Walsh KS, Gioia GA, Wolters PL, Tonsgard J, Schorry E, Viskochil D, Klesse L, Fisher M, Gutmann DH, Silva AJ, Hunter SJ, Rey-Casserly C, Cantor NL, et al. (2016) Randomized placebo-controlled study of lovastatin in children with neurofibromatosis type 1. Neurology 87:25752584 .

Pnevmatikakis EA, Giovannucci A (2017) NoRMCorre: an online algorithm for piecewise rigid motion correction of calcium imaging data. J Neurosci Methods 291:83-94.

Ribeiro MJ, Violante IR, Bernardino I, Edden RA, Castelo-Branco M (2015) Abnormal relationship between GABA, neurophysiology and impulsive behavior in neurofibromatosis type 1. Cortex 64:194-208.

Sale A, Maya Vetencourt JF, Medini P, Cenni MC, Baroncelli L, De Pasquale R, Maffei L (2007) Environmental enrichment in adulthood promotes amblyopia recovery through a reduction of intracortical inhibition. Nat Neurosci 10:679-681.

Sale A, Putignano E, Cancedda L, Landi S, Cirulli F, Berardi N, Maffei L (2004) Enriched environment and acceleration of visual system development. Neuropharmacology 47:649-660.

Schridde U, Strauss U, Bräuer AU, Van Luijtelaar G (2006) Environmental manipulations early in development alter seizure activity, Ih and HCN1 protein expression later in life. Eur J Neurosci 23:3346-3358.

Schrimsher GW, Billingsley RL, Slopis JM, Moore BD (2003) Visual-spatial performance deficits in children with neurofibromatosis type-1. Am J Med Genet 120A:326-330.

Shah MM (2014) Cortical HCN channels: function, trafficking and plasticity. J Physiol 592:2711-2719.

Shilyansky C, Karlsgodt KH, Cummings DM, Sidiropoulou K, Hardt M, James AS, Ehninger D, Bearden CE, Poirazi P, Jentsch JD, Cannon TD,
Levine MS, Silva AJ (2010) Neurofibromin regulates corticostriatal inhibitory networks during working memory performance. Proc Natl Acad Sci USA 107:13141-13146.

Siegel F, Heimel JA, Peters J, Lohmann C (2012) Peripheral and central inputs shape network dynamics in the developing visual cortex in vivo. Curr Biol 22:253-258.

Silva AJ, Frankland PW, Marowitz Z, Friedman E, Laszlo GS, Cioffi D, Jacks T, Bourtchuladze R, Lazlo G (1997) A mouse model for the learning and memory deficits associated with neurofibromatosis type 1. Nat Genet 15:281-261.

Sommeijer JP, Levelt CN (2012) Synaptotagmin-2 is a reliable marker for parvalbumin positive inhibitory boutons in the mouse visual cortex. PLoS One 7:e35323.

Stivaros S, Garg S, Tziraki M, Cai Y, Thomas O, Mellor J, Morris AA, Jim Carly, Szumakska-Ryt K, Parkes LM, Haroon HA, Montaldi D, Webb N, Keane J, Castellanos FX, Silva AJ, Huson S, Williams S, Evans DG, Emsley R, et al. (2018) Randomised controlled trial of simvastatin treatment for autism in young children with neurofibromatosis type 1 (SANTA). Mol Autism 9:12.

Stosiek C, Garaschuk O, Holthoff K, Konnerth A (2003) In vivo two-photon calcium imaging of neuronal networks. Proc Natl Acad Sci USA 100:7319-7324.

Sugiyama S, Di Nardo AA, Aizawa S, Matsuo I, Volovitch M, Prochiantz A, Hensch TK (2008) Experience-dependent transfer of Otx2 homeoprotein into the visual cortex activates postnatal plasticity. Cell 134:508-520.

Trachtenberg JT, Stryker MP (2001) Rapid anatomical plasticity of horizontal connections in the developing visual cortex. J Neurosci 21:3476-3482.

Trachtenberg JT, Trepel C, Stryker MP (2000) Rapid extragranular plasticity in the absence of thalamocortical plasticity in the developing primary visual cortex. Science 287:2029-2032.

Triplett JW, Wei W, Gonzalez C, Sweeney NT, Huberman AD, Feller MB, Feldheim DA (2014) Dendritic and axonal targeting patterns of a genetically-specified class of retinal ganglion cells that participate in imageforming circuits. Neural Dev 9:2.

van der Vaart T, Plasschaert E, Rietman AB, Renard M, Oostenbrink R, Vogels A, de Wit MC, Descheemaeker MJ, Vergouwe Y, CatsmanBerrevoets CE, Legius E, Elgersma Y, Moll HA (2013) Simvastatin for cognitive deficits and behavioural problems in patients with neurofibromatosis type 1 (NF1-SIMCODA): a randomised, placebo-controlled trial. Lancet Neurol 12:1076-1083.

Williams VC, Lucas J, Babcock MA, Gutmann DH, Korf B, Maria BL (2009) Neurofibromatosis type 1 revisited. Pediatrics 123:124-133.

Winnubst J, Cheyne JE, Niculescu D, Lohmann C (2015) Spontaneous activity drives local synaptic plasticity in vivo. Neuron 87:399-410.

Xu H, Furman M, Mineur YS, Chen H, King SL, Zenisek D, Zhou ZJ, Butts DA, Tian N, Picciotto MR, Crair MC (2011) An instructive role for patterned spontaneous retinal activity in mouse visual map development. Neuron 70:1115-1127.

Yang SS, Li YC, Coley AA, Chamberlin LA, Yu P, Gao WJ (2018) Cell-type specific development of the hyperpolarization-activated current, Ih, in prefrontal cortical neurons. Front Synaptic Neurosci 10:7. 